\title{
Dual Cellular-Path (MIHP) Healthy Urbanism - Justifying, Peacebuilding Surveillance at Borderlands / Kinmen
}

\author{
Li-Yen Hsu ${ }^{1, *}$ \\ HSU Studio, Head Architect; liyenhsu@ms19.hinet.net \\ * Correspondence: liyenhsu@ms19.hinet.net; Tel./Fax.: : +886-3-571-5523
}

\begin{abstract}
Holistic information integrity for managing wicked problems, developing equity is getting attention. Artificial intelligence based topologies, dual sensor-information nodes, are prototyped to offer more availability, reliability, maintainability for operating healthy urbanism. Bipartite spider-webs, cube-connected cycles are aimed in the radial-ring urban-building skeleton' and 'wetlands and sparsely populated areas', respectively. Furthermore, honeycomb tori, mathematical $\mathrm{HT}(\mathrm{m}), \mathrm{m} \geq 2$, for tasks related to wireless communications, are found having two mutually independent Hamiltonian paths (MIHP). This parallelism creates dual cipher-coding, supports logistic privacy, and helps prevent information distortion due to interferences, faults caused by such as clogged water.
\end{abstract}

Keywords: availability; cipher coding; clogged water; honeycomb tori; maintainability; mutually independent Hamiltonian paths (MIHP); interference; privacy; reliability; wicked problems

\section{Introduction}

In 1851, a building, Crystal Palace, was built with iron and glass for the first World Fair exhibition held in London [1] (pp.15-23). That innovative project was featured with efficient construction and space adaptability (or flexibility), having airy, bright, and green interior atmosphere or being more healthful than most buildings of that time [2] (pp.121-125), [3] (pp.32-33). Quality like healthy and adaptability consequently can get more interest, and create the beginning of modern urbanism.

This international style has been rationally promoted [4] (p.112) since caring customers' economic demand or the highest affordable utility has been accommodated. Nevertheless, various aspirations accompanied with empathy had been gotten concerns since 1970s, including on billboard aesthetics [5] (Fig. 1(a,b)). In the total life cycle of the built-up, adaptability is the critical quality on humanistic care - providing, health, safety, energy [6,7], economy [2,8], and related knowledge [8-10] (Fig. 1) - for living in contemporary era of resource restriction proactively toward net-zero economy [11,12].

Besides spatial configurations, adaptable multi-disciplinary personnel collaboration is highly needed, including for those whom must be cared of, and even remotely for countering pandemics like the COVID-19 [13] (p. 138), [14-16]. Pure autonomy is impractical, and the access-controlled fence is needed [16], [17] (p.287). Dealing with such challenges are assisted generally through "visible and invisible" (or roughly wired and wireless) "sensor-information" (abbreviated as S-I) [18,19] systems. Real-time intelligence on holistically dealing with ambiguousness, which can be due to blind-spots, image occlusion, and electromagnetic interference [12] (p.14), [20] (p.266), is needed. 


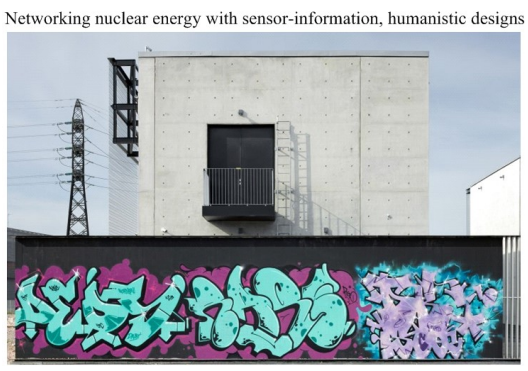

(a)

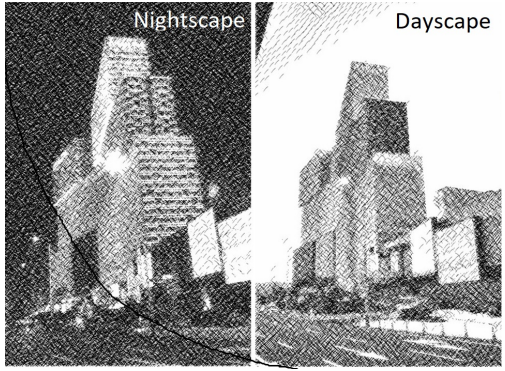

(b)

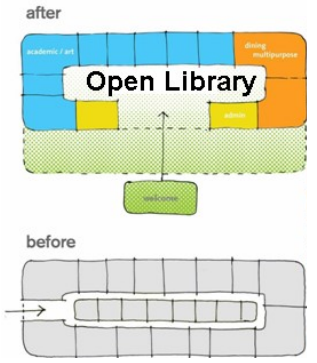

(c)

Figure 1. Sensor - information networking highly needed, e.g., (a) in trust-building, electricity substation (linked with nuclear power), Helsinki; (b) in developing (night-time) economy, casino (with simple cuboids), Macau; (c) in environmental control, library (with a rectangular renovated plan), Los Angels.

\section{Scopes}

\subsection{Healthy City Demanded in This Century}

The 'healthy city' was initiated by the World Health Organization, and its complexity had been publicized in the 2012 Lancet Commission. Its principles can be recognized as the following: (1). Availability - collaborating urban health through a wide range of stakeholders. (2). Equity - promoting inclusiveness as the key focus of health policy. (3). Maintainability - aggressively creating and maintaining the urban advantage in health outcomes. (4). Intelligence - proactively handling a complexity analysis to well know relations affecting urban health consequences. (5). Reliability scientifically proceeding towards effective action on urban health. [4] (pp.7-8), [21] (p.26)

Since the life-threatening pandemics, terrorist attacks, and other environmental issues in the context of 'healthy city' developing have already been noticed [11] (p.125), [21] (p.60), technologies and relational facts need to be developed resiliently [15,19,22,23]. Without sacrificing the sense of welcome, sustainable environmental control with holistic intelligence in planning healthy settlements is getting more attention [24] (p.357), [25], [26] (p. 86), [27] (p.8). Such security related collaboration needs experts' alertness and holistic knowledge contributions [24,28]. Nevertheless, urban 'wicked problems', which, as Rittel \& Webber 1973, are hardly forecast, formulated, or responded in real-time, can ubiquitously exist [29-31].

Hence, that such availability, inherited with the adaptability to well respond uncertain spatial-temporal conditions is rational [32,33]. Innovative, effective methods, including mathematical prototyping [30,31,34] and design [30,31,35], can naturally be considered. The first step of urban planning [29], goal formulation, is better to be studied through the assistance of cybernetic infrastructure. Nevertheless, the availability or inclusiveness has been claimed in the Lancet Commission, forming holistic considerations through public participation, the topology (i.e., the way in which constituent parts are interrelated or arranged) effectiveness, or the efficiency of S-I network is essential.

Consequently, the prevailing invisible cellular communication related network pattern [36] is analyzed in Section 3.2. Such wireless communications largely applied in urbanism have started since this century, and are critically for developing small drones, autonomous vehicles. Considering the pros and cons of applying emergent S-I technologies to promote social infrastructure should be proactive, i.e., from strategic 'smart cities' and 'ITS' (intelligent transportation systems) perspectives [28,37-39]. In summary, this prototyping is oriented to spatial adaptation, or related to topology-the science of patterns [26,34]; those denoting regularity are much interested in. 


\subsection{Mathematical Integrity}

Pattern topology had been studied by L. Euler in 1736, on planning a stroll tour of passing through every bridge exactly once for 'Seven Bridges of Königsberg;' - i.e., there were two islands abreast in the river-the smaller island had three bridges, the larger one had five bridges, totally seven bridges - the two islands were connected each other by one bridge. Graphically, to the upper and lower riverbank areas of Königsberg, the two (upper and lower) shores of two islands similarly had one and two bridges respectively.

This above mentioned Euler's planning has four nodes (or places) and seven links (bridges), only one node (i.e., the larger island) has five links, and others each has three links. Because leaving from each node can be linked by even number of links yet the total number of links being seven, thus planning such a tour had been proved impractical. This kind of problems is generalized as Eulerian circuit or an undirected graph that traverses each link of the graph exactly once [40] (p. 79).

In contrast, an undirected graph that passes through each node of the graph exactly once can be a Hamiltonian cycle if the first node and the last node connected with one link or a Hamiltonian path if the first node and the last node are not connected [40] (p. 141). A node can represent a work unit (e.g., device maintaining), and the link can represent the connection between two work units. Handling all work units one by one accountably is efficient and effective if no repetition or loss exists; such project can be analyzed as finding a Hamiltonian path or Hamiltonian cycle. Hamiltonian graphs are known having computation complexity, or difficult solving characterization [40] (p. 141)essentially similar to the aforementioned wicked problems.

Seeing that the performance on relational patterns can be confirmed through mathematical justifications, prototyping on promoting spatial performance can be developed with pattern configuring followed with mathematical analysis. On healthy urbanism, human's safety (dominated by self-control) and security (affected by intrusion) is confronted basically with person's sense organs, e.g., two eyes, two ears, two nostrils, and the combination of more than one sense including touch feeling. Both tolerance and integrity are clearly shown in living creatures' sensory mechanism. Thus, dual surveillance or plural surveillance can be considered analogically in the S-I networks $[18,19]$, with high security and integrity intentioned pattern configuring. Surveillance devices of both line-of-sight (possible direction-varying) and non-line-of-sight (or radio) modes can be applied together; i.e, device availability is reasonably hoped.

Intended for the aforementioned maintainability, the pattern configuring of S-I networks applies Hamiltonian properties to inspect, repair devices systematically without loss. On the aforementioned reliability, fault-tolerance is considered, also in the field of graph theory. Generally, the whole S - I network prototyping is toward being an holistic trust-building and knowledge promotion oriented infrastructure.

\subsection{Place-making synergism of cyber infrastructure}

Well community can be featured with social coordination and supply of various demand through the assistance of $S$ - I systems; besides, can manage natural ventilation, day lighting, planting, waste [25,41,42], utilities, and other operational tasks of built environments. Advanced modes, such as the high speed vacuum tube train, autonomous passenger air vehicles, and unmanned aerial vehicles (UAV) or drones $[43,44]$ are highly expected to help control carbon emissions, and urbanisation [39,45-47]; nevertheless, to positively develop sustainable scattered land-uses [48], to gain resilient resource utilization [49], as well as to increase more urban mobility is hoped.

Except for built environments, well personnel collaboration, which generally needs truthfulness, is essential in task responsiveness. Hence, education or training cannot be negotiated [10,50]; moreover, well human resource chain should be collaborated through human care [51,52]. Especially facing the necessity to create resources [53] (p. 112), [54], 
trust building or the interest of synergism is the foundation of successful place-making [55-58]. The above comprehensiveness can be simplified and presented in Fig. 2. To ensure radio S-I integrity, sensing availability, reliability, and flexible spatial connectivity (Fig. 3), designing spatial patterns of holism [19], [26] (p. 86) is essential, including to support wireless communication for vehicles $[59,60]$.

(a)

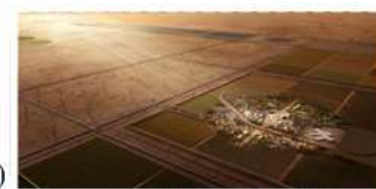

(b)

(c)

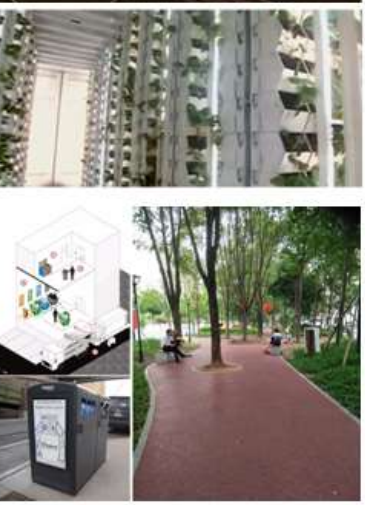

Flexible

- Land-Use

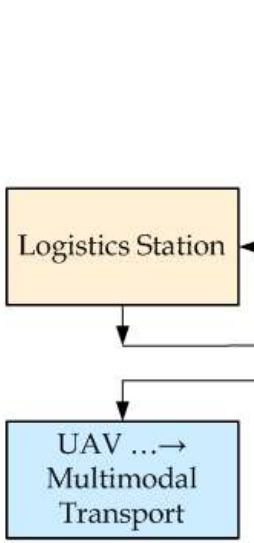

- Health \& Security •

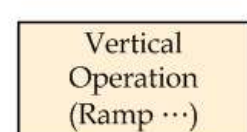

Flexible Connection

Figure 2. Urbanism chained with intelligence, e.g., (a) Energy: suburbanisation, desert transformation; (b) Food: shipping container as vegetable plant; (c) Health: green sidewalk with smart reverse logistics; (d) Education: affordable, autonomous school car; (e) Synergism: livable essentials designed in supply chains; (f) Mobility: drone and smart road.

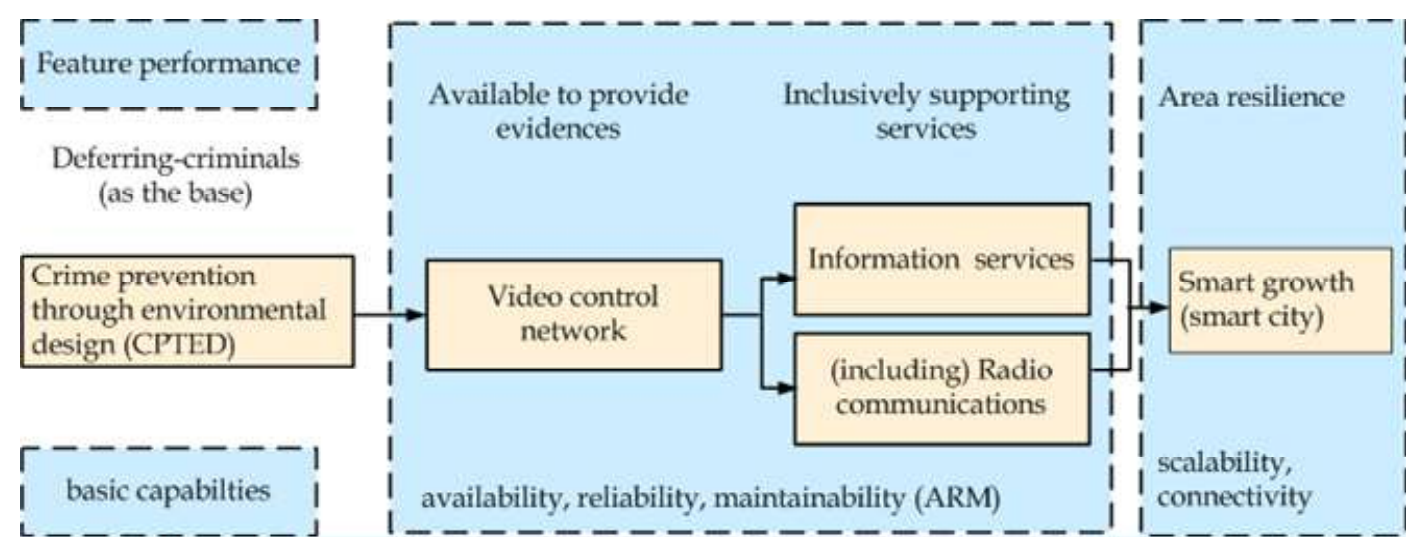

Figure 3. Enhancing smart urban growth with sensor-information resilience.

On considering incident truthfulness and responsiveness, plural (dual) surveillance collaborated with 'multiple-input multiple-output' (MIMO) technologies has been widely utilized in various environments [2] (p. 113), [18,61] (Fig. 4). To support resilience in live streaming, systematic maintenance, and dynamic cipher coding on privacy protection can be rationally operated through order and parallelism (Fig. 5) i.e., through applications of 'mutually independent Hamiltonian paths' (MIHP) [40] properties (Section 3).

Spider-web (SW) [40] networks are prototyped along (main) paths, which can be the radial-ring and essentially the very adaptable, resilient urban-building skeleton $[19,62,63]$. Moreover plural surveillance based cube-connected cycles are prototyped for deploying in wetlands and sparsely populated areas $[19,49]$; honeycomb tori (HT) are 
studied for promoting aerial vehicles flying over off-paths [64] (p.215) through cellular communication [10].

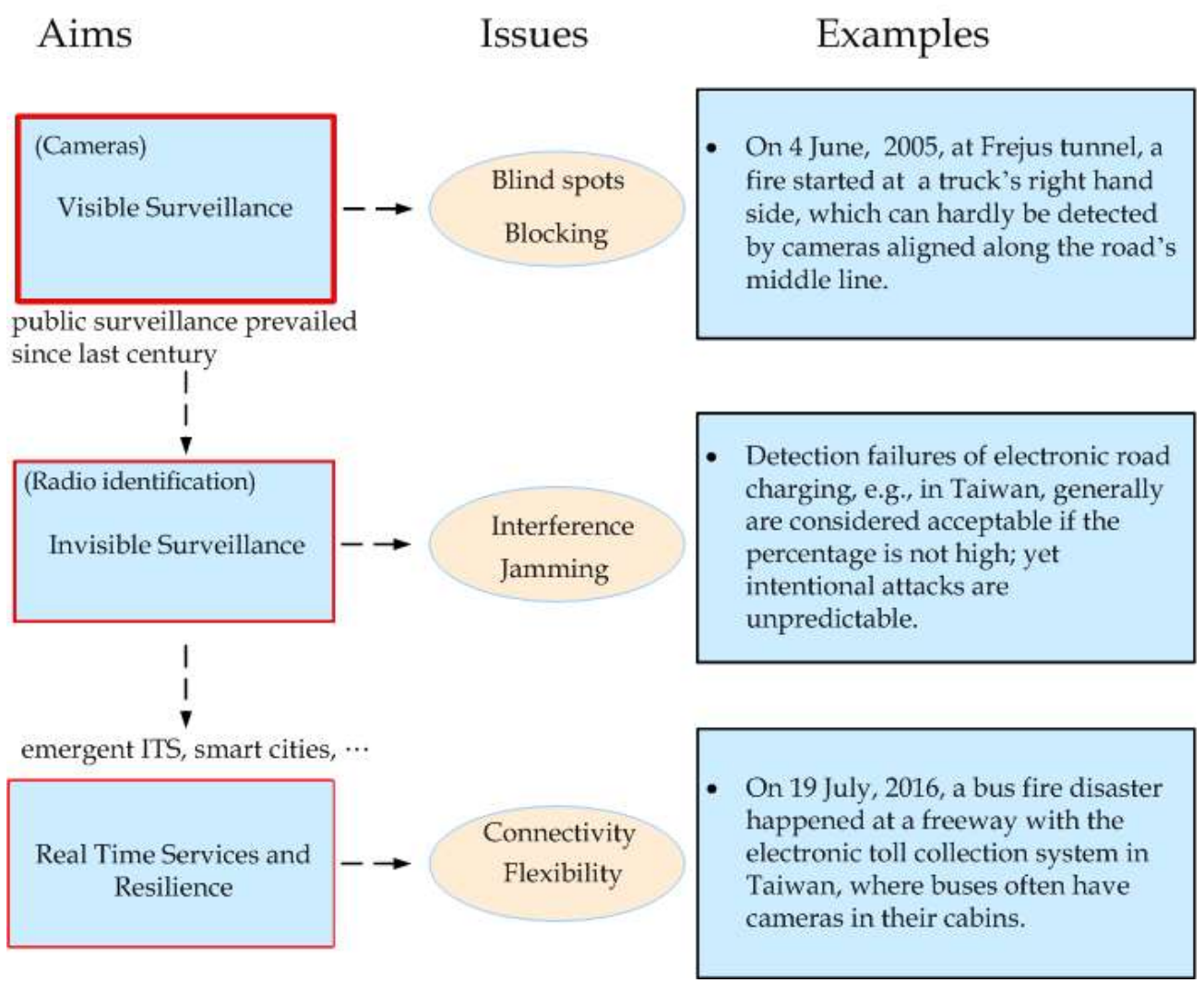

Figure 4. Evolving holistic S-I networks with dual (plural) surveillance.
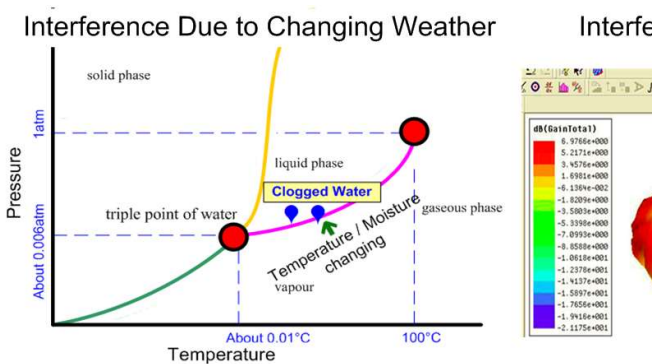

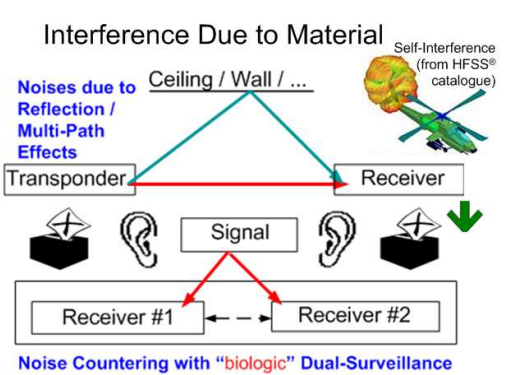

(a)

MIHP can help analyze interference $(\mathcal{N}$ ) or offer the dynamic cipher coding in maintenance inspection

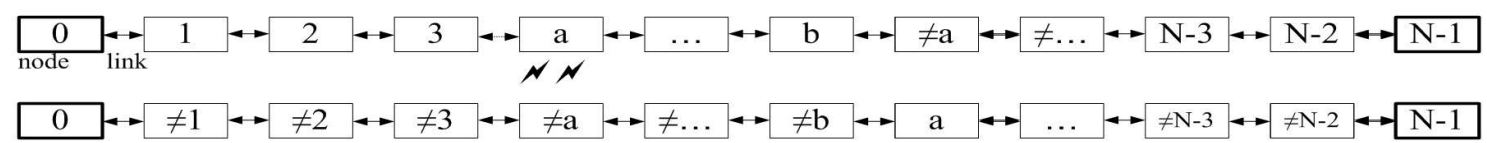

(b)

Figure 5. Diagnosing interference and ciphering to promote privacy via MIHP, shown as: (a) potential interference reasons; (b) diagnosing interference and privacy ciphering via MIHP.

\section{Method}

Just as people's using two (dual) eyes, two ears, and other sensory organs, real-time reliable surveillance needs availability for such as countering blind spots, distinguishing slight differences, and message confirming, which are critically related to accompanied node fault-tolerance, node reliability, or binarity. Based on such binarity in 
promoting availability and reliability, S-I networking with three types is further structured with link reliability, systematic maintainability, adaptability to benefit holistic information integrity, at present (including on path, water, air, indoor).

\subsection{AI oriented prototyping - developing dependable availability}

Disasters mentioned on Fig. 4, can justify that artificial intelligence (AI) based prototyping; just as humans' multi senses, plural (dual) S-I surveillance can benefit dealing with unexpected incidents. More specifically, olfactory bio-sensors can be accommodated to help prevent smuggling, bombs, and fires $[19,65]$. This can also justify designing a reliable networking prototype with adaptability. A consensus [19] has been reached regarding the establishment of the resilient roadside dedicated short-range communications (DSRC) [37] for problems mentioned.

Through analysis of acquired data for different positions and corresponding time sequences by using MIHP (Fig. 5; see Section 3.2) $[10,19,49]$ so that interferences (including those due to radio frequency or material properties), radio multi-path effects, and possible other unexpected faults can be cared. A series of such plural (dual)-surveillance S-I nodes could be arranged along a path (Fig. 6) at positions with worthy of attention to dynamically support thorough recordings, transmissions, and to feature diagnostic responses or alarms owing to such systematic, comparable parallelism.

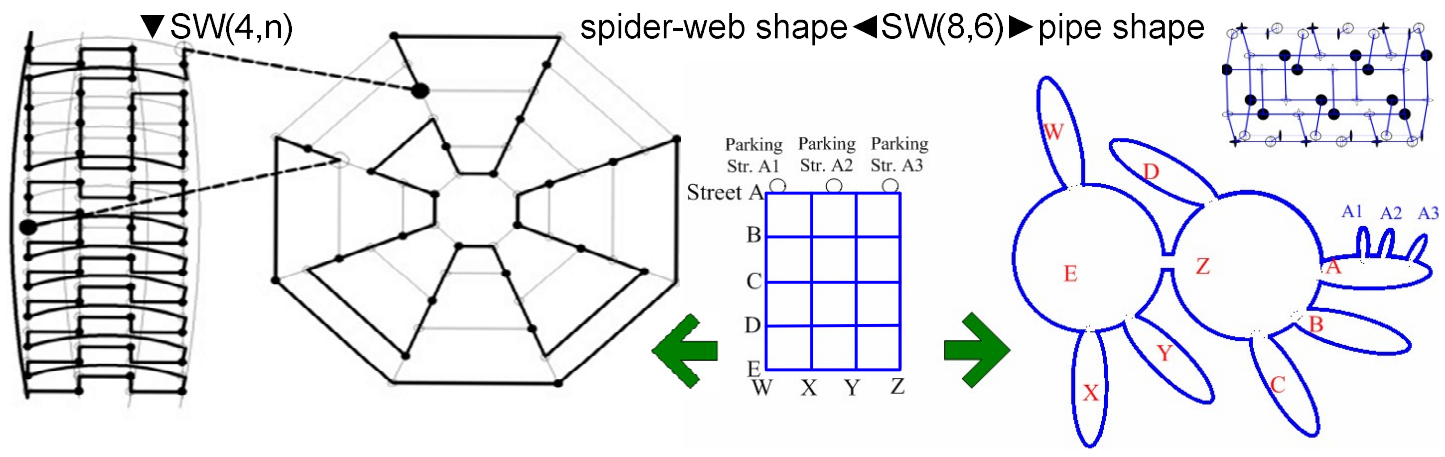

$\diamond$ Holism Resilience (SW network-of-networks)

Integrative Parking / Vehicle Management

Figure 6. Spider-web network applications:, area-based DSRC networks.

Except for difficulties of countering boat collisions, smuggling, and expelling other potential hazards in relatively less noticed terrains, waterways can have very adverse conditions owing to water's physical, radio interference possibilities [66-68]. Hence, surveillance for this type of S-I networks generally is waterborne based $[19,69,70]$ (Fig. $5,7)$. Monitored vehicles or entities can be concealed behind or camouflaged with other entities. Accidents are often resulted from communication and/or surveillance faults. Moreover, terrorists often target crowded places, such as airports, for attacks at any time and any location even concurrently occur at several different locations. Consequently, plural (dual)-surveillance-based S-I networks are more appropriate for busy or critical passages, including for waterways.

Surveillance's employing parallel mechanisms, which may already exist on airports' air-sides, can help prevent airport incidents. Collaborative fault-tolerant radars or groups of multiple sensors can be deployed at airfields to overcome sensitive problems due to such as blind spots, false images, and to quickly repair facilities. Nevertheless, such capabilities can be further improved by S-I networks' holistic performance. Generally, an area-based resilient S-I network [19,49] systematically integrates sensory devices along the path, and at exterior or interior positions; besides, cellular communications, global positioning systems, and geographic information systems are integrated (Fig. 6-8). 
Such networks can be adapted for facilitating S-I operations including when one lane of a path is under maintenance, and for accommodating forward, backward surveillance directions, probably different scopes. Moreover, such networks are scalable; they can be designed to add the number of lanes in a path section, and to be extended along a path or survey area (e.g., water) to flexibly response future requirements [19].

Honeycomb tori can be expected to manage the traffic of unmanned aerial vehicles (or drones). That they can hardly be detected by the roadside surveillance due to their being small and probably very far, is getting more concerns [19,64]. Such drones are being considered to be legally utilized, e.g. for logistic application; however, they should be detectable, manageable along each lane of the path, as well as in areas off roadside surveillance.

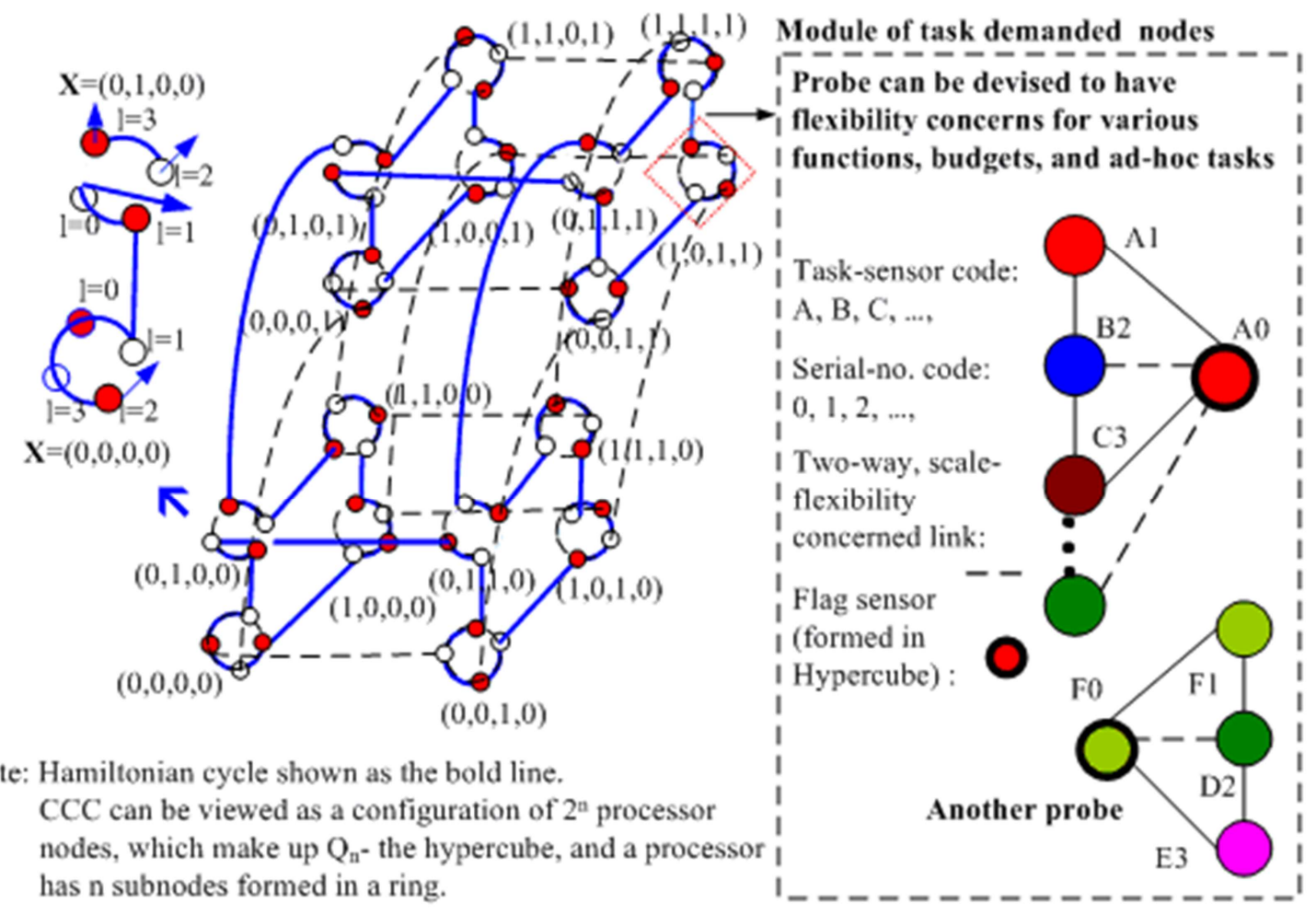

(a)

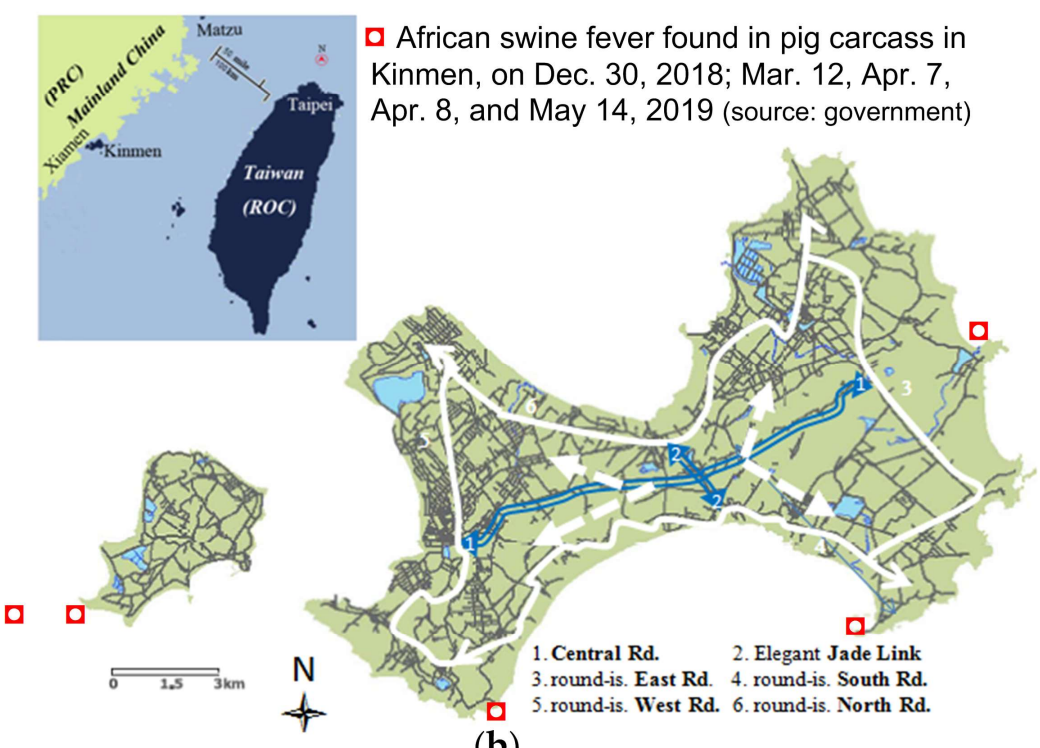

(b)

Figure 7. Buoyant probe perspectives, shown as: (a) relationship between cube-connected cycles (CCC) and hypercubes, e.g., with $\mathrm{CCC}_{4}$ and the ring networked module; (b) an evidence of forward-thinking on dealing with issues of cross-border health and security. 
The number of links connecting a node is called the degree; networks that regularly have lower degrees are generally economic [71]. The mathematical regular optimal-degree (degree being three, the minimal links to a node to fit dual-surveillance requirements along a busy path) spider-web (SW) network is prototyped to build wireless or heterogeneous sensor-information networks on paths (Fig. 6), and a special interference-free cellular communications [19,36] off paths. Another degree-three Honeycomb torus (HT) network, which is isomorphic to the generalized Honeycomb torus (GHT) network [40,72], is prototyped for general cellular communication applications (Fig. 8). Their fault tolerance (properties: 1-edge Hamiltonian and 1p-Hamiltonian; see next sub-section) that can be used for enhancing maintenance efficiency and effectiveness [73] is proposed.

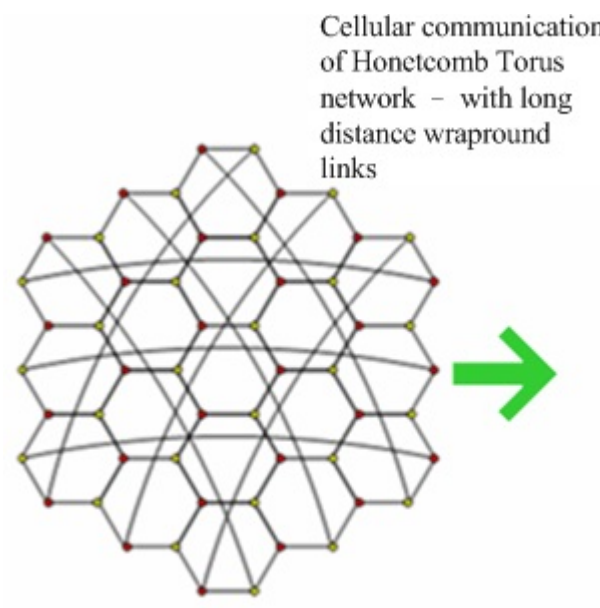

Honeycomb Torus, $\mathrm{HT}(\mathrm{m})=>\mathrm{GHT}(\mathrm{m}, 6 \mathrm{~m}, 3 \mathrm{~m})$

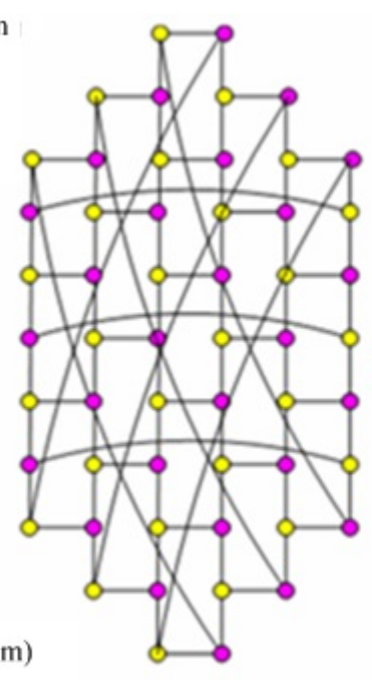

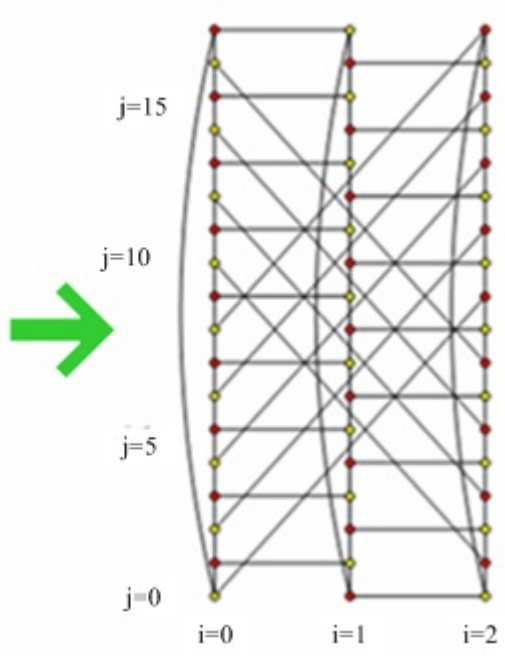

Figure 8. Evolution .of generalized honeycomb tori from honeycomb tori.

\subsection{Mathematical Evidence - highlighting connectivity, maintainability, and reliability}

Let $\mathrm{D}=(\mathrm{V}, \mathrm{E})$ be a graph if $\mathrm{V}$ is a finite set and $\mathrm{E}$ is a subset of $\{(\mathrm{a}, \mathrm{b}) \mid(\mathrm{a}, \mathrm{b})$ is an unordered pair of $\mathrm{V}\}$. A path is delimited by $\left(\mathrm{x}_{0}, \mathrm{x}_{1}, \mathrm{x}_{2}, \ldots, \mathrm{x}_{\mathrm{n}-1}\right)$. A path is called a Hamiltonian path if its nodes are distinct and span V. A cycle is a path of at least three nodes such that the first node is the same as the last node. A cycle is called a Hamiltonian cycle or Hamiltonian if its nodes are distinct except for the first node and the last node, and if they span $\mathrm{V}$ [40].

A bipartite graph $D=(V, E)$ is a graph such that $V=A \cup B$ and $E$ is a subset of $\{(a, b)$ $\mid \mathrm{a} \in \mathrm{A}$ and $\mathrm{b} \in \mathrm{B}\}$; if $\mathrm{D}-\mathrm{F}$ remains Hamiltonian for any $\mathrm{F}=\{\mathrm{a}, \mathrm{b}\}$ with $\mathrm{a} \in \mathrm{A}$ and $\mathrm{b} \in \mathrm{B}$, then $\mathrm{D}$ is $1_{\mathrm{p}}$-Hamiltonian. A graph $\mathrm{D}$ is a 1-edge Hamiltonian if $\mathrm{D}$ - $\mathrm{e}$ is Hamiltonian for any $e \in E$. Moreover, if there is a Hamiltonian path between any pair of nodes $\{c, d\}$ with $c \in A$ and $d \in B$, then the bipartite graph $D$ is Hamiltonian laceable. Notably, laceability is used with respect to connectivity to ensure that extended areas are integrated (or vice versa) and an area can be managed hierarchically yet effectively.

The bipartite spider web (SW) network (Fig. 6) is proved to be 1-edge Hamiltonian and 1p-Hamiltonian [40,74]. Thus, the fault tolerance involved is systematically based (i.e., prototyped to capably deal with unexpected incidents at any time and location, including several locations concurrently). Moreover, $\mathrm{SW}(\mathrm{m}, \mathrm{n})$ is Hamiltonian laceable [75], Fig. 6.

The cube-connected cycle graph, $\mathrm{CCC}_{\mathrm{n}}$, has $\mathrm{n} 2^{\mathrm{n}}$ nodes labelled as $(l, x)$, where $l$ is an integer between 0 and $\mathrm{n}-1$ and $x$ is a processor node with an n-bit binary string. That $\mathrm{n}$-bit binary string can also be the basis of a hypercube, $Q_{n}[40]$, which consists of $2^{\mathrm{n}}$ nodes but $\mathrm{n} 2^{\mathrm{n}-1}$ links (Fig. 7(a)). If $u=b_{n-1} \ldots b_{i} \ldots b_{0}$ be an $n$-bit binary string, for any $j, 0 \leq$ $j \leq n-1$, let $(u)^{j}$ denote the binary string $b_{n-1} \ldots b_{j} \ldots b_{0}$. In $\mathrm{CCC}_{\mathrm{n}}$, two nodes $(l, x)$ and $\left(l^{\prime}, \boldsymbol{y}\right)$ 
are adjacent if and only if $x=y$ and $\left|l-l^{\prime}\right|=1$ or $l=l^{\prime}$ and $y=(x)^{l}$. In the $l=l^{\prime}$ case, $\mathrm{x}$ and y only differ in position $l$. The edges that connect $(l, x)$ to its neighbours $(l+1, x)$ and $(l-$ $1, x)$ are cycle edges. These cycle edges form a cycle called a fundamental cycle of length $\mathrm{n}$, naturally with link fault-tolerance, and is defined by $x$, which can represent a probe (or a node) composed of ring-networked processors. $\mathrm{L}(\mathrm{n})$ is the set of all possible lengths of the cycles in $\mathrm{CCC}_{n}(\mathrm{Fig} .7(\mathrm{a}))$. For $\mathrm{n}=2, \mathrm{CCC}_{\mathrm{n}}$ is simply a cycle graph of length 8 .

Two Hamiltonian paths, $\mathrm{P}_{1}=\left(\mathrm{u}_{1}, \mathrm{u}_{2}, \ldots, \mathrm{u}_{\mathrm{n}}(\mathrm{D})\right)$ and $\mathrm{P}_{2}=\left(\mathrm{v}_{1}, \mathrm{v}_{2}, \ldots, \mathrm{v}_{\mathrm{n}}(\mathrm{D})\right)$, of $\mathrm{D}$ from $\mathrm{u}$ to $\mathrm{v}$ are independent if $\mathrm{u}=\mathrm{u}_{1}=\mathrm{v}_{1}, \mathrm{v}=\mathrm{u}_{\mathrm{n}}(\mathrm{D})=\mathrm{v}_{\mathrm{n}}(\mathrm{D})$, and $\mathrm{u}_{\mathrm{i}} \neq \mathrm{v}_{\mathrm{i}}$ for every $1<\mathrm{i}<$ $\mathrm{n}(\mathrm{D})$. A set of Hamiltonian paths, $\left\{\mathrm{P}_{1}, \mathrm{P}_{2}, \ldots, \mathrm{P}_{\mathrm{k}}\right\}$, of $\mathrm{D}$ from $\mathrm{u}$ to $\mathrm{v}$ are mutually independent if any two distinct paths in the set are independent from $u$ to $v$ [76]. SW(m, n) was found to exhibit the MIHP performance between any pair of bipartite nodes [19,49] (Fig. 5). Notably, MIHP is considered for fault or interference diagnosing, and dynamically providing ciphered information, which can offer real-time private information to secure logistic, transportation operation and protect public welfare.

Honeycomb tori, $\mathrm{HT}(\mathrm{m}) \mathrm{m} \geq 2$, have the same node sets as planar honeycomb meshes, $\operatorname{HM}(\mathrm{m})$, but with regular node degree being three by having wraparound links. Generalized honeycomb tori, GHT(m, n, d), d being any integer, $(\mathrm{m}-\mathrm{d})$ and $\mathrm{n}$ being even, are the graph with 1-edge Hamiltonian if $n \geq 4$; 1p-Hamiltonian if $n \geq 6$ or $m=2, n \geq 4$ [77], and Hamiltonian laceable [78]. GHT( $\mathrm{m}, 6 \mathrm{~m}, 3 \mathrm{~m})$ is isomorphic to honeycomb tori, HT(m) (Fig. 8) [10,72].

Hence, assuring that MIHP phenomenon exists in the honeycomb configurations to enhance the application in wireless communication [36] is studied from generalized honeycomb tori, GHT(m, n, d), $n \geq 4, d=n / 2$. Five types are studied and aimed at $n \geq 12$, and each type can be classified into three sub-types. This study is shown as the legend and the other following figures (Fig. 9-24).

\section{$\bigcirc, \bigcirc$ : biparsite node, general \\ $\square, \square$ : linear extension (LE) $\mathbf{0}$ : column code}

$05(0 \mathrm{~J})$ : two digit node code (change color due to XE; J=10, e.g. ) - --- : link of basic network
O, О (ㅁ, ㅁ): endnode (w. LE)
$\boldsymbol{\nabla}:$ insertion of LE
05 : LE available

: embedding link (exclude XE)

: Hamiltonian path link of basic network

8 : module for (left / right direction) embedding (red, upper side; blue, lower side) shown with the (left

/ right) superscript.; adaptation, i.e., a pair of LE, highlighted with underline

$\mathrm{x}: \mathrm{X}$ extension (XE) available; the embedding affected by XE is, generally double-underline, highlighted

: XE link (hidden line for marking adaptation; topologically $\mathrm{X}$ configuration presented with)

Figure 9. Legend.

\section{Phenomenon-Dual MIHP in Cellular Communication Pattern, HT}

Just as many other studies, testing and observing along with adjustments and designs is needed. Each of all five types contains limited nodes, and only arithmetical techniques need to be used (but time and care is needed). After the comparable dual path patterns (Fig. 10-24) being established, achieving scalability can be assured because embedding location and direction can have quite enough flexibilities to achieve a well composition. A mathematical explanation for all figures in this section is shown in Appendix.

4.1. Type $A-$ even $m \geq 2 ; l$ (end-node horizontal distance) $=0,2 \leq l \leq d-2$, or $d$; end-node columns' width-separation odd 


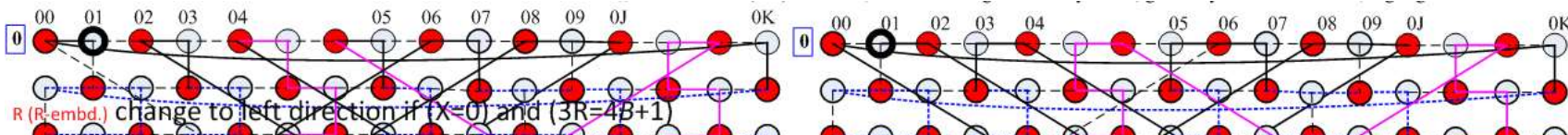

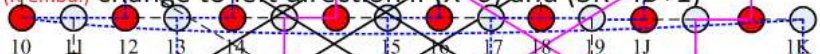

$0000-0 \times 0-000000$

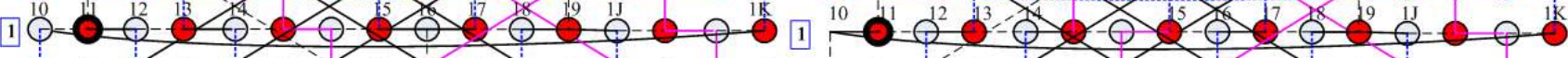

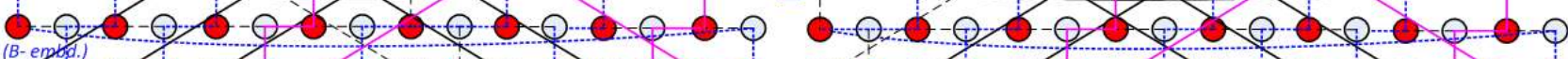

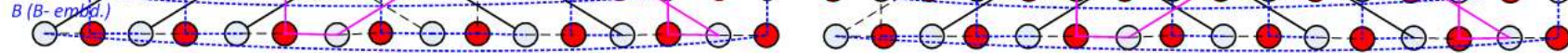
$01,00,0 \mathrm{~K}^{8} \mathrm{P} 1 \mathrm{~K}, 10^{4} 06,07^{48} 17,16,15^{44} 05_{\mathrm{x}} 04^{4} 1 \mathrm{~J}, 19,18^{8} 02,03^{84} 13,14^{4} 0 \mathrm{~J}, 09,08^{4} 12,11 \mathrm{Lt}$. $01,02^{4} 18,19,1 \mathrm{~J}^{4} 04,03^{84} 13,12^{8} 08,09,0 \mathrm{~J}^{4} 14_{\mathrm{x}} 15^{44} 05,06,07^{48} 17,16^{4} 00,0 \mathrm{~K}^{8}{ }^{8} 1 \mathrm{~K}, 10,11 \mathrm{Rt}$.

Figure 10. GHT(even $m \geq 2, n \geq 12, d=n / 2$ ), MIHP, end-nodes at 2 col., separation odd, $l=0$.

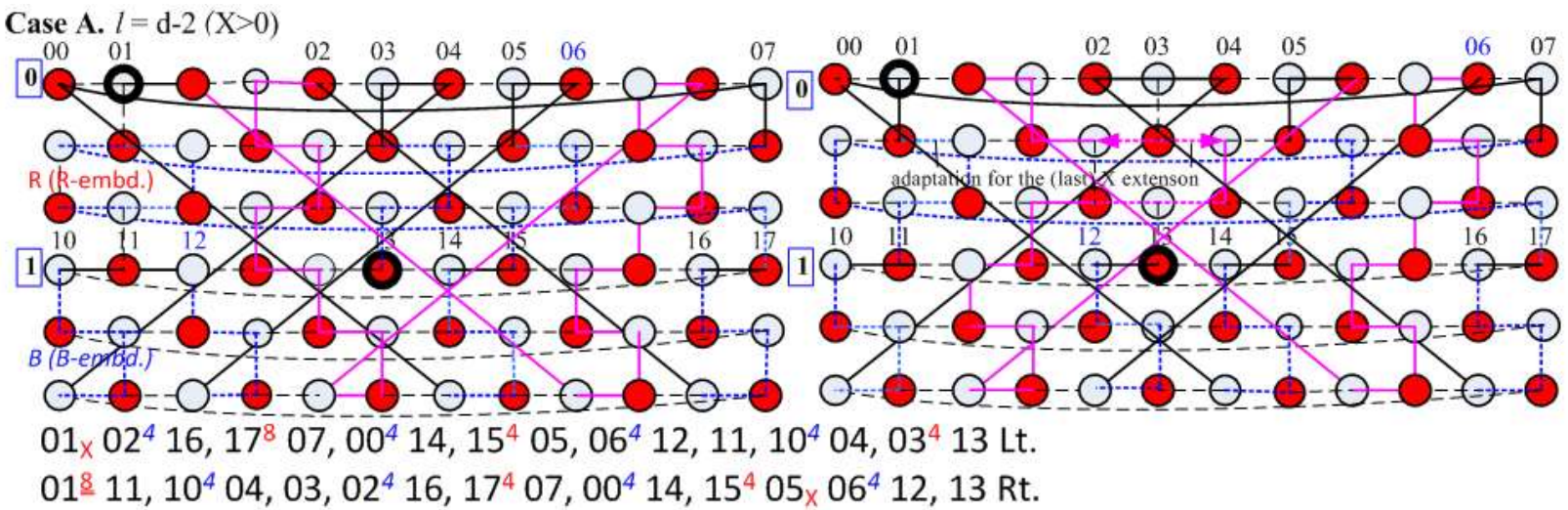

Case B. $2 \leq l \leq \mathrm{d}-4(\mathrm{X}>0)$
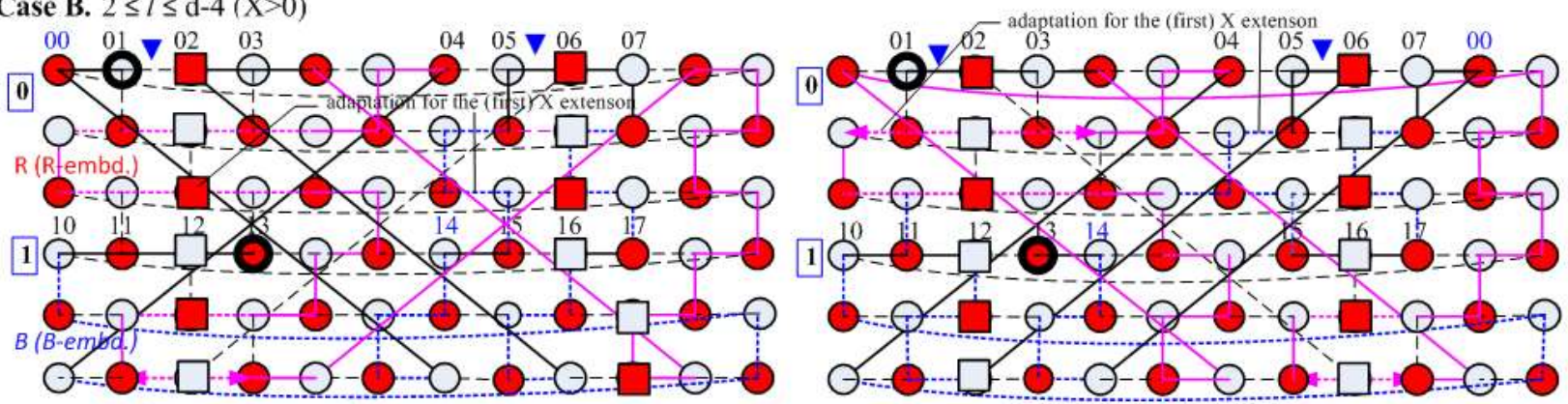

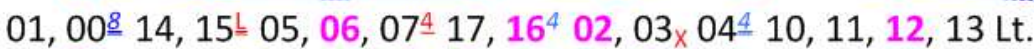

$01,02,03 \times 04 \stackrel{8}{2} 10,11,12^{4}-06,05^{\mathrm{L}} 15,16,17 \stackrel{4}{4} 07,00^{4} 14,13 \mathrm{Rt}$.

Figure 11. GHT(even $\mathrm{m} \geq 2, \mathrm{n} \geq 12, \mathrm{~d}=\mathrm{n} / 2$ ), MIHP, end-nodes at 2 col., separation odd, $2 \leq \mathrm{l} \leq \mathrm{d}-2$.

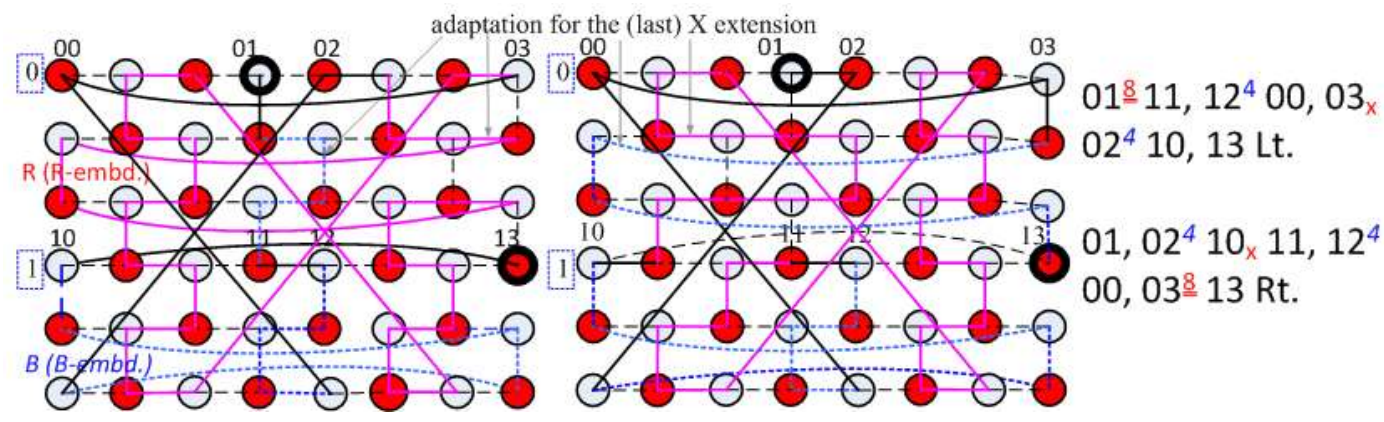

Figure 12. GHT(even $m \geq 2, n \geq 4, d=n / 2)$, MIHP, end-nodes at 2 col., separation odd, $\mathrm{l}=\mathrm{d}$. 
Case A. $n>12$
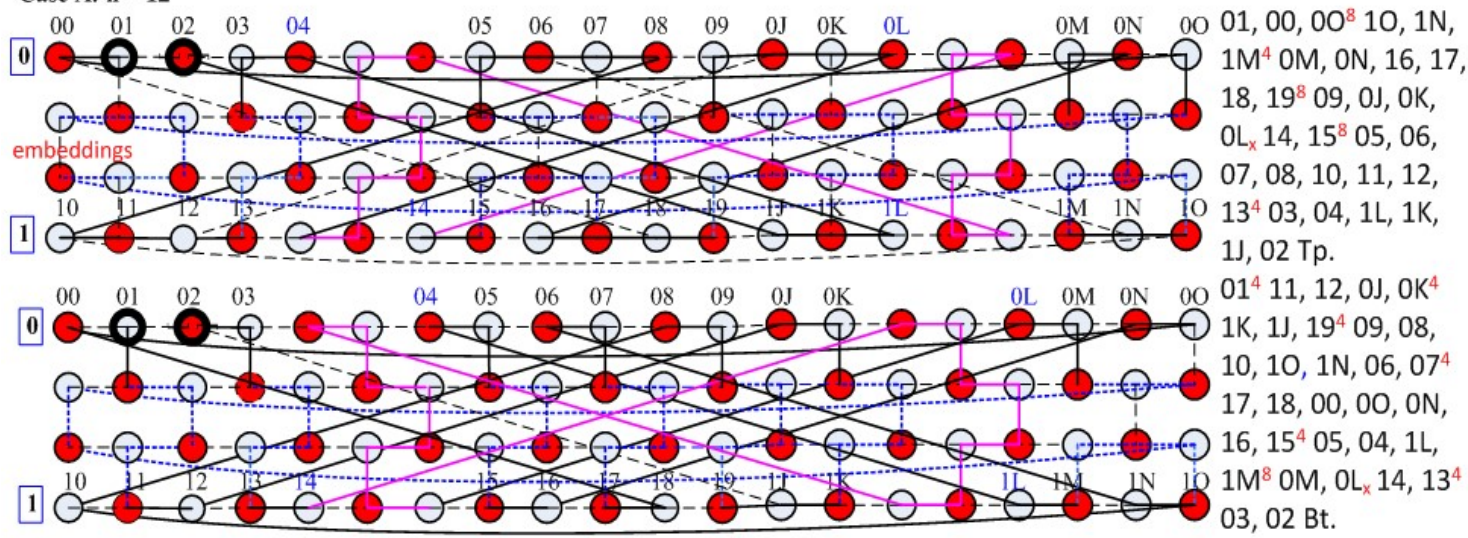

Case B. $n=12$

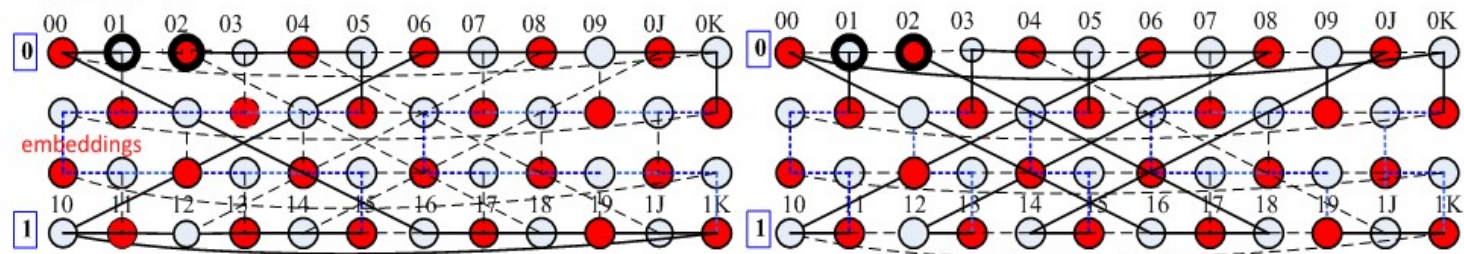

$01,00,16,17,18,19,1 \mathrm{~J}, 1 \mathrm{~K}^{\llcorner} 0 \mathrm{~K}, 0 \mathrm{~J}, 09,08,07,06,10,11,12,13,14,15^{\mathrm{L}} 05,04,03,02 \mathrm{Lt}$.

$01^{4} 11,10,06,07,08,12,13^{4} 03,04,05^{4} 15,14,0 \mathrm{~J}, 09^{8} 19,1 \mathrm{~J}, 1 \mathrm{~K}^{4} 0 \mathrm{~K}, 00,16,17,18,02 \mathrm{Rt}$.

Figure 13. GHT(even $m \geq 2, n \geq 12, d=n / 2$ ), MIHP, end-nodes at the same col., $l=1$.

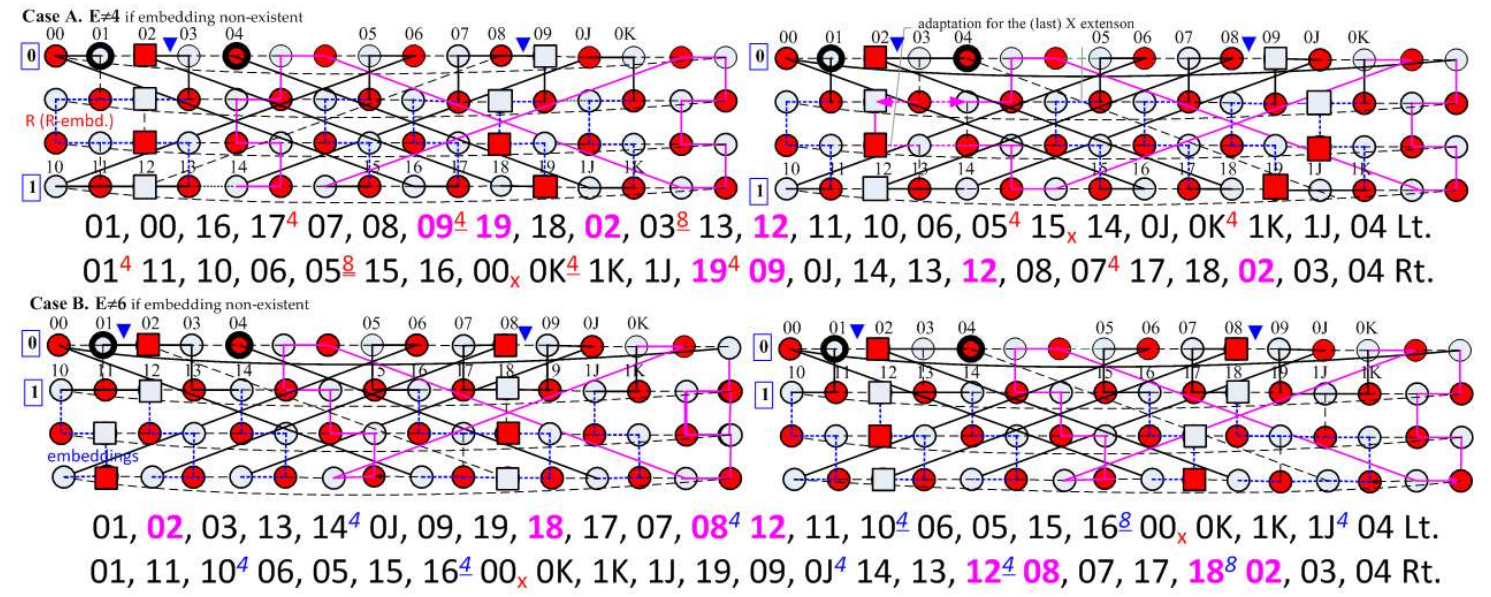

Figure 14. GHT(even $m \geq 2, n \geq 12, d=n / 2$ ), MIHP, end-nodes at the same col., $3 \leq 1 \leq d-3$

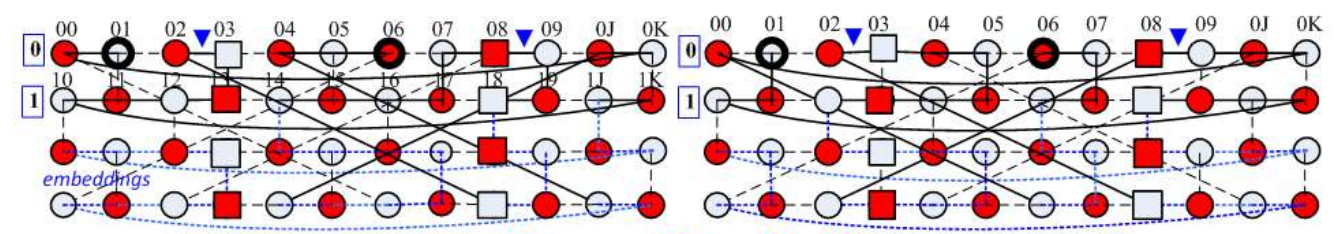

$01,00,0 \mathrm{~K}, 0 \mathrm{~J}^{8} 14,15,16,17,07,08,09,19,184$ 02, 03, 13, 12, 11, 10, 1K, 1J느 04, 05, 06 Lt. $01,11,10,1 \mathrm{~K}, 1 \mathrm{~J}, 19,18 \stackrel{\mathrm{L}}{0}$, 03, 04, 05, 15, 14, 13, $12^{\stackrel{8}{8}}$ 08, 09, 0J, 0K, 004 16, 17, 07, 06 Rt.

Figure 15. GHT(even $m \geq 2, n \geq 12, d=n / 2$ ), MIHP, end-nodes at the same col., $1=d-1$. 


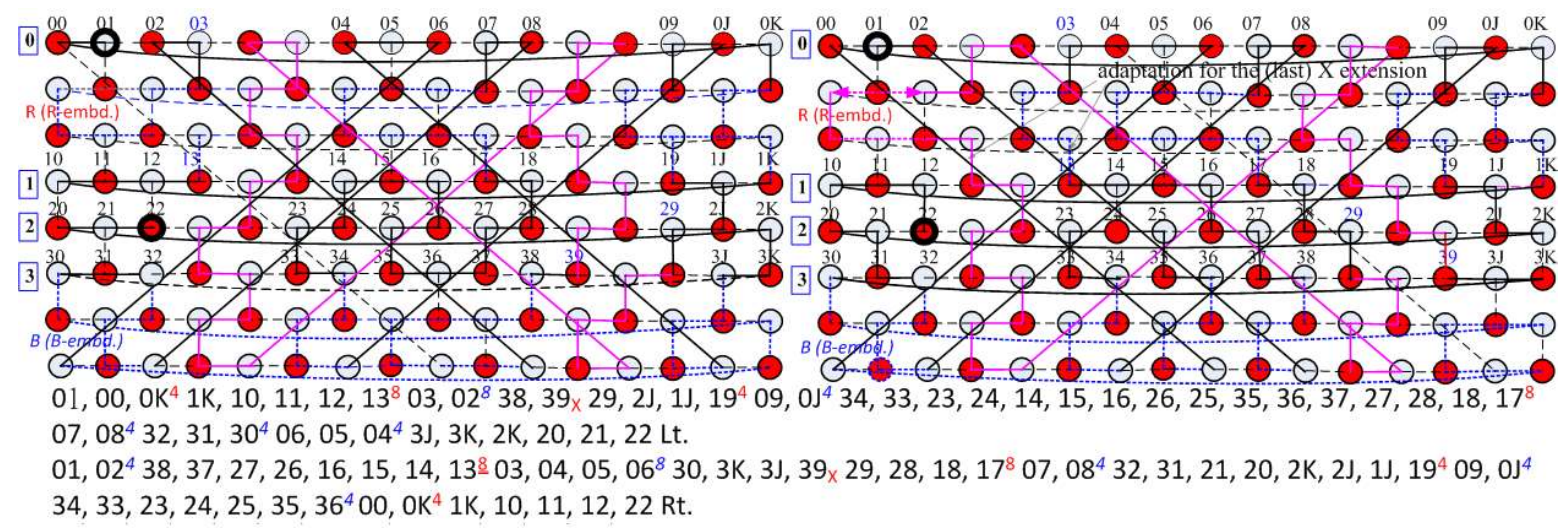

Figure 16. GHT(even $m \geq 4, n \geq 12, d=n / 2$ ), MIHP, end-nodes at 2 col., separation even, $\mathrm{l}=1$.

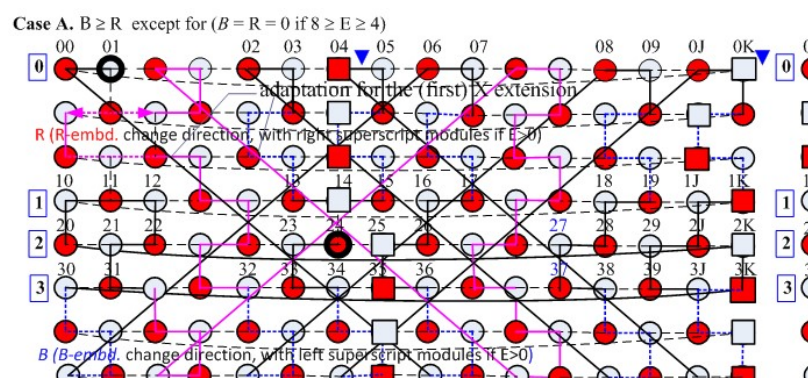

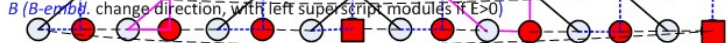

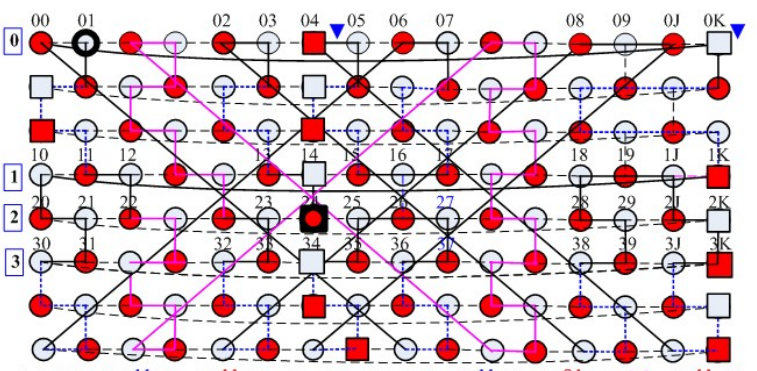

$01,00^{4} 436,35,25,26,16,17^{44} 07,06^{4} 30,3 K, 2 K, 20,10,11,12,22,21,31 \times 32^{44} 08,09^{44} 19,18,28,27,37,38^{44} 02,03^{\frac{84}{4}} 13,14,15^{44} 05$, $04^{4} 43 \mathrm{~J}, 39,29,2 \mathrm{~J}, 1 \mathrm{~J}, 1 \mathrm{~K}^{4} 8 \mathrm{~K}, 0 \mathrm{~J}^{4} 434,33,23,24 \mathrm{Lt}$.

$01^{44} 11,12,22 \times 23,33,32^{44} 08,09,0 \mathrm{~J}^{44} 34,35,25,26,27,37,36^{44} 00,0 K^{84} 1 \mathrm{~K}, 10,20,21,31,30^{44} 06,07^{48}-17,16,15^{44} 05,04^{44} 3 \mathrm{~J}, 3 \mathrm{~K}, 2 \mathrm{~K}$, 2J, $1 \mathrm{~J}, 19,18,28,29,39,38^{44} 02,03^{44} 13,14,24 \mathrm{Rt}$.
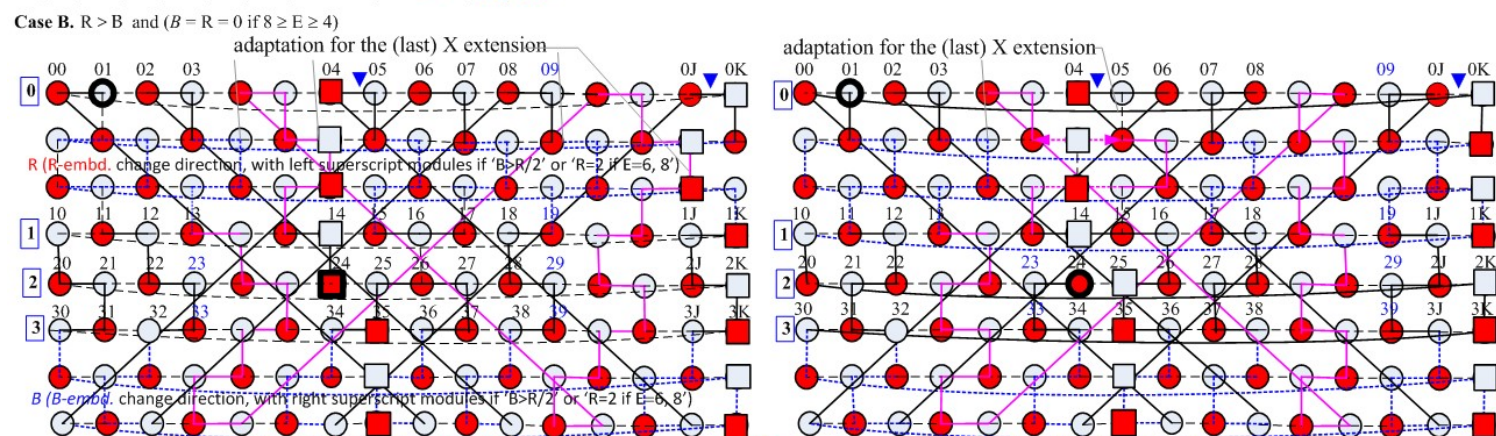

$01,00^{44} 36,37,27,26,25,35,34^{44} 0 \mathrm{~J}, 0 \mathrm{~K}^{4}{ }^{4} 1 \mathrm{~K}, 1 \mathrm{~J}, 2 \mathrm{~J}, 2 \mathrm{~K}, 3 \mathrm{~K}, 3 \mathrm{~J}^{44} 04,05^{44} 15,16,17^{44} 07,06^{4} 30,31,21,20,10,11,12,22,23,33,32^{44}$ $08,09^{44} 19,18,28,29,39,38^{44} 02,03^{84} 13 \times 14,24 \mathrm{Lt}$.

$01^{44} 11,12,22,21,31,32^{44} 08,07^{8} \stackrel{4}{1} 7,18,28,27,37,38^{44} 02,03^{48}-13 \times 14,15,16,26,25,35,36^{44} 00,0 K^{44} 1 \mathrm{~K}, 10,20,2 \mathrm{~K}, 3 \mathrm{~K}, 30^{\underline{4}} 06,05$, 044 $43 \mathrm{~J}, 39,29,2 \mathrm{~J}, 1 \mathrm{~J}, 19^{44} 09,0 \mathrm{~J}^{4} \leq 34,33,, 23,24$ Rt.

Figure 17. GHT(even $m \geq 4, n \geq 12, d=n / 2)$, MIHP, end-nodes at 2 col., separation even, $3 \leq 1 \leq d-3$.

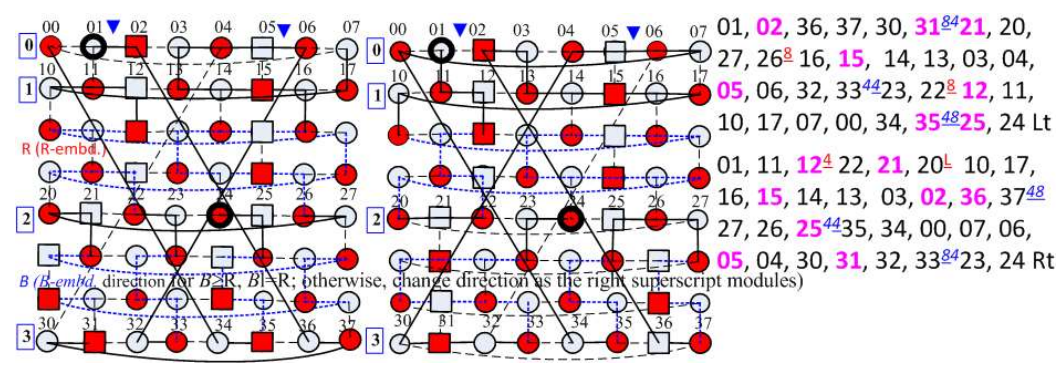

Figure 18. HT(even $m, n \geq 8, d=n / 2)$, MIHP, end-nodes at 2 col., separation even, $\mathrm{l}=\mathrm{d}-1$.

4.4. Type $D$ - odd $m \geq 3 ; l: 0, d-1$, or $2 \leq l \leq d-3$; end-nodes at different columns 


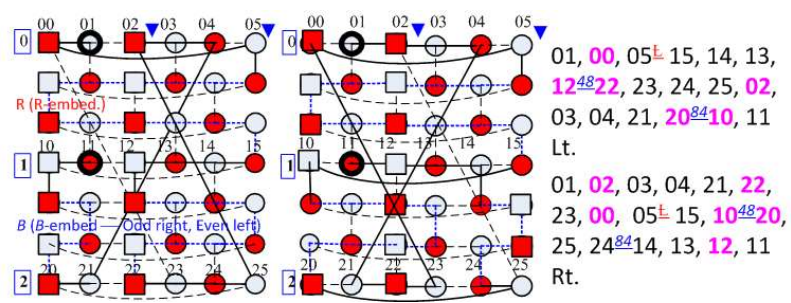

Figure 19. $G H T$ (odd $m \geq 3, n \geq 6, d=n / 2)$, MIHP, end-nodes at 2 col., $l=0$ ( $(=12$ plus a pair of LE).

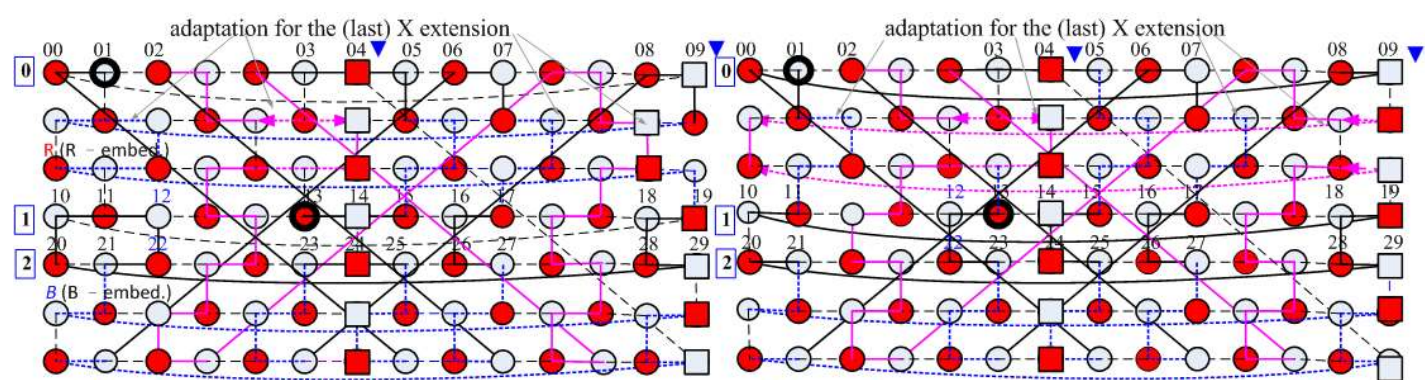

$01,00^{4} 25,24,23^{4} 08,09=19,18,28,29,20,10,11,12,22,21^{8}=06,07^{4} 17,16,26,27^{4} 02 \times 03,04,05^{4} 15,14,13$ Lt. $01^{\stackrel{8}{-}} 11,10,19,18,28,29,20,21^{\stackrel{8}{8}} 06,07^{-}-17,16,26,27^{4} 02 \times 03,04,05^{4} 15,14,24,25^{4} 00,09,08^{4} 23,22,12,13$ Rt.

Figure 20. GHT(odd $m \geq 3, n \geq 10, d=n / 2$ ), MIHP, end-nodes at 2 col., $2 \leq 1 \leq d-3$.

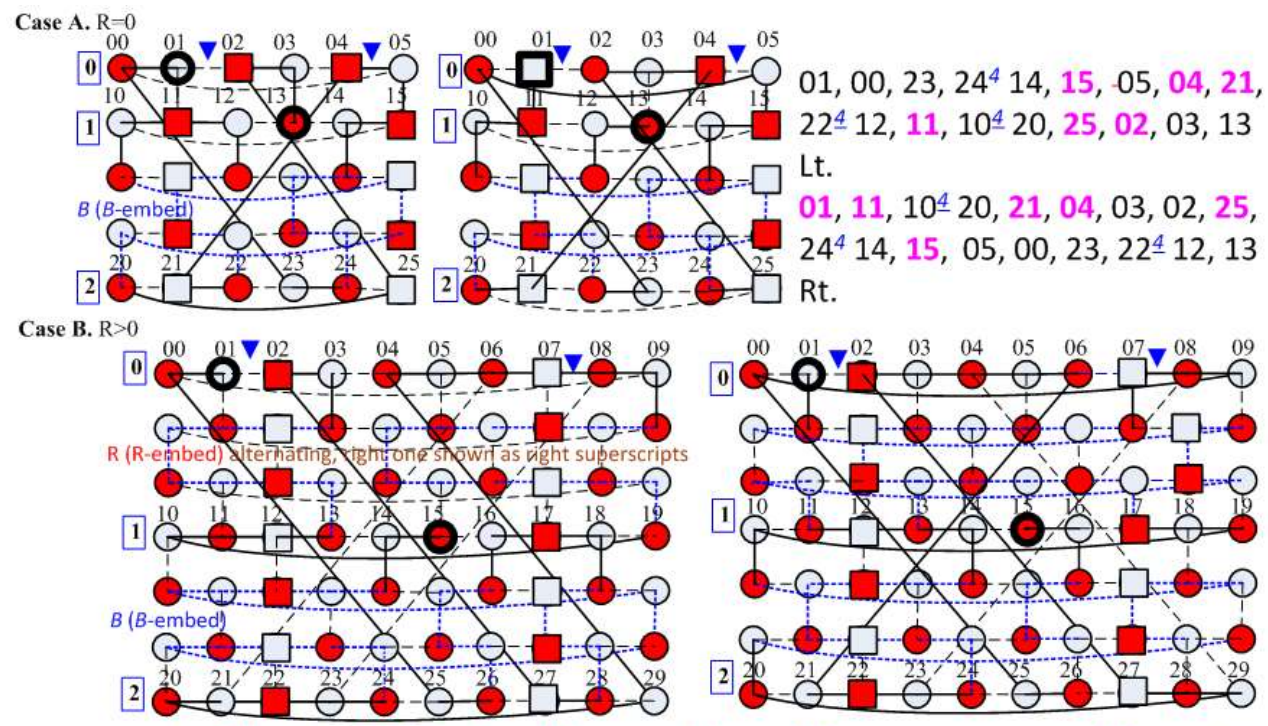

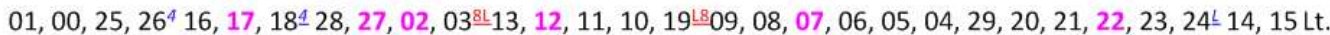
$01^{4 \mathrm{P}} 11,12,13,14^{8} 24,23,22,21,06,05,04,03,02,27,28,29,20^{-8} 10,19,18,17^{\mathrm{P} 4} 07,08,09,00,25,26^{4} 16,15$ Rt.

Figure 21. GHT(odd $m \geq 3, n \geq 10, d=n / 2)$, MIHP, end-nodes at 2 col., $\mathrm{l}=\mathrm{d}-1$.

4.5. Type $E-$ odd $m \geq 3 ; l: 0, d-1$, or $2 \leq l \leq d-3$; encodes at same column
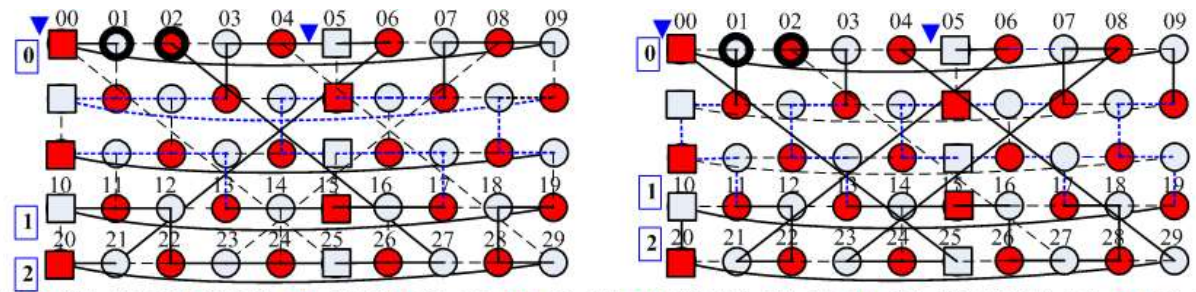

$01,00,09,08,07 \stackrel{8}{1} 17,16,15,14,13$ 는 $03,04,05,06,21,20,29,28,18,19,10,11,12,22,23,24,25,26,27,02$ Lt.

Figure 22. GHT(odd $m \geq 3, n \geq 10, d=n / 2)$, MIHP, end-nodes at same col., $1=1$. 


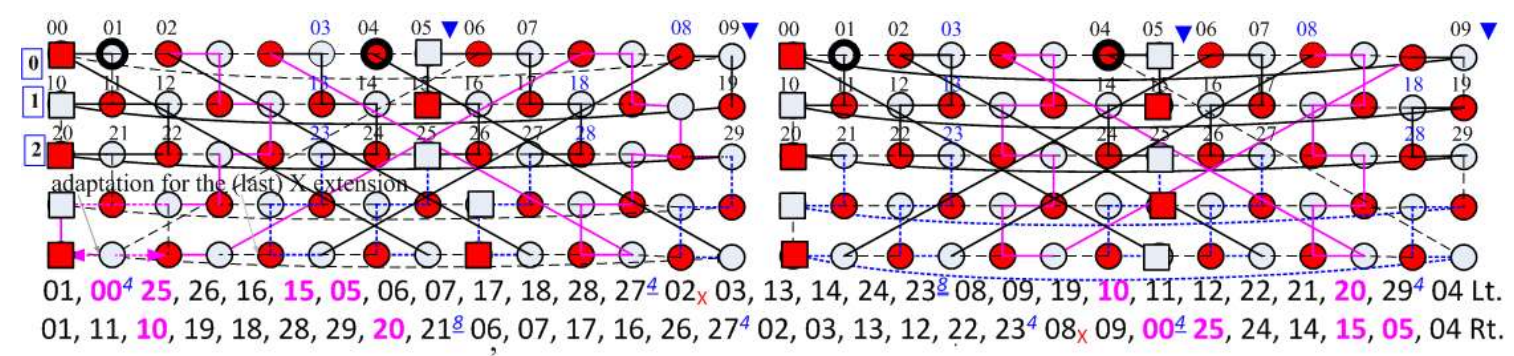

Figure 23. GHT(odd $m \geq 3, n \geq 10, d=n / 2)$, MIHP, end-nodes at same col. $2 \leq 1 \leq d-3$.

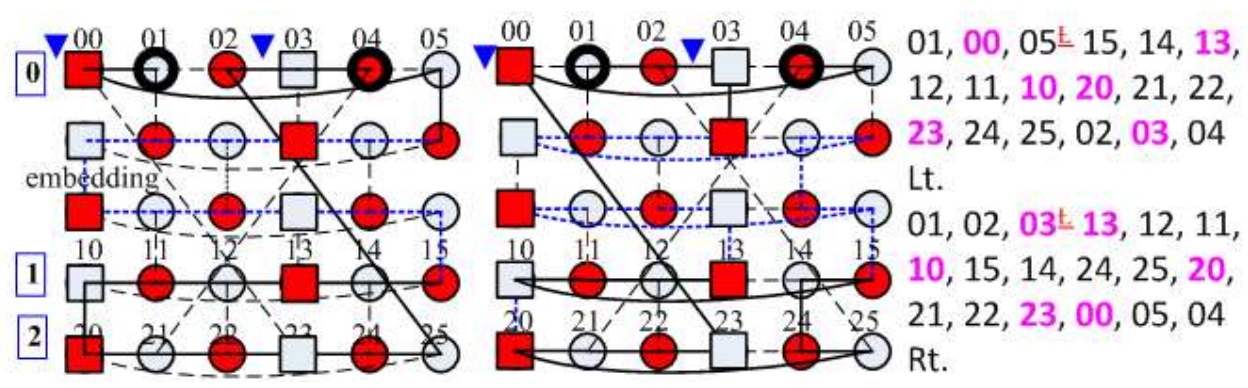

Figure 24. GHT( odd $m \geq 3, n \geq 6, d=n / 2)$, MIHP, end-nodes at same col. $1=d(E=12+$ a pair of LE).

\section{Discussions}

\subsection{Further Parallelism Research}

In the MIHP search study, the composition of embeddings and extensions can be considered topologically as evolved nodes of the basic pattern. Observation and trials are needed at present; heuristic means are applied as the following: (a) same direction, (b) blocking, (c) non-divisibility, (d) reasonable linear extension, (e) reasonable X-helix extension, (f) reasonable network configuration, and (g) effective combination. Applying present experiences on shape studies, which are related to embedding locations and directions, to get ideal configurations through computing is considered a future work.

\subsection{Resilient Urbanism Developed Through Living Features}

Seeing that wicked, global changing related disasters, have happened more frequently, the appropriateness of plural (dual) surveillance approach of the ITS seemingly needs to be studied. Similar to people's using two eyes, two ears, and other sensory, a real-time reliable surveillance need such creatures' environmental managing mechanism, i.e., availability,to counter blind spots, to distinguish small differences, to confirm receiving messages, and/or to care node fault-tolerance or node reliability. In prototyping systematic availability, the methodology of this research can be described as design based.

Effective maintainability of a relative large amount of nodes, especially on those security related ones, should care the sequential inspection without loss and repetition [73]; such operation is the proved mathematical Hamiltonian. The Hamiltonian cycle also can support some edge fault-tolerance (reliability); more fault-tolerance can be supported through 1-edge Hamiltonian and/or 1p-Hamiltonian, which can casually help the network element's repairing (different from the need of the probe application). Proved laceability of the bipartite SW and GHT network helps establish network hierarchies and the aerial, morphological connectivity, or space adaptability in promoting smart urban growth. The cube-connected cycle is considered for the probe application; it can support availability on both terms - Hamiltonian and plural surveillance. Prototyped mathematical models can also support scalability, which helps 
accommodate different conditions, such as on adjusting the path expansion, extension and the traffic facilities.

\subsection{Mobility Enhanced Through Resilient Wireless Systems}

The incorporation of spider-webs and honeycomb iori, e.g., with MIHP, can potentially increase operational flexibility, integrity promotion, and privacy related cipher coding for cellular or wireless S-I systems as in [19] and Fig. 8. The VANET (vehicular ad-hock network in ITS) through stochastic passing vehicles' assistance can easily have missing. To promote radio information integrity along paths, dedicated short range communications (DSRC) are needed and plural (dual) surveillance approach is suggested [19]. Advancing surveillance control technologies interacted with cellular communications, e.g., for managing radio-advanced unmanned vehicles are more needed nowadays. Consequently, the MIHP performance of SW and HT can benefit the privacy protection from the coding through the active radio frequency identification [19]. Plural (dual) surveillance nodes can be incorporated with MIMO technologies and cellular communications to have their inherent application possibilities.

In general, prototyped mathematical networks are with fault tolerance, Hamiltonian order, connectivity, scalability, countering electromagnetic interference, protecting privacy through cipher coding, and reliable accuracy through plural (dual) detection. Moreover, the grid path pattern can be adapted to the radial-ring pattern [62], with which the spider-web network prototype can consequently form a resilient area (path) network of (sensor-information) networks, which offers dependable networking holism (availability, reliability, and maintainability) [73, 79-81], flexibility (future land-use coordination), adaptability (transportation, logistic coordination) [19], and synergism. Thus, providing three types of sensitive and reliable sensor-information networks incorporated with contemporary cellular communications for place security and development is proposed.

\section{Conclusions}

In challenging contemporary societies, sound globalization, economic dependability for surfing resources and confronting complexities is needed. Through artificial intelligence oriented distributed computing and mathematical integrity, sensor-information networks are prototyped intentionally for ubiquitous, humanistic spatial management. Spider-webs and cube-connected cycles are aimed in the radial-ring urban-building skeleton' and 'wetlands and sparsely populated areas', respectively.

Honeycomb Tori, proved having two mutually independent Hamiltonian paths, are prototyped for further service enhancing, including those surveillances on modern small drone with wireless, cellular communications. Evidences can indicate that plural-surveillance based networking of availability, reliability, maintainability, and morphological connectivity to respond urban wicked problems in real-time is critical. Trustworthy operation of maintenance, dynamic cipher coding of privacy assurance, or countering interference (e.g., caused by clogged water) can be through the platform of order and parallelism.

Such mutually independent Hamiltonian path properties, and adaptable scalability, reliability, can benefit developing proactive suburbanisation economy, remote yet holistic interactions, cross-border transport/logistics, and temporary but care sensitive facilities. AI network patterns on changing urbanism, including perspectives of health, utility effectiveness, safety, and/or peace are consequently promoted.

Appendix-Mathematical Explanation of Section 4

In GHT formation, MIHP can probably not be easily found in some cases, whose end nodes are 'adjacent' and vertical dimension or the total number of nodes is 
relatively small. The honeycomb (hexagonal) torus $\operatorname{HT}(2)$ is isomorphic to $\operatorname{GHT}(2,12,6)$. Especially after MIHP being justified on 'Fig. 10 of Type A ( $\mathrm{n}=12$ and R-embed=0)' and 'Fig. 13 ( $\mathrm{n}=12$ ) of Type B' (next sub-section), whose end-nodes are adjacent in GHT, the honeycomb torus, $\mathrm{HT}(\mathrm{m})$ and $\mathrm{m} \geq 2$, have fully MIHP performance can be expected.

On Fig. 10, R-embed needs two directions to support in-dependency. Lt $0 \mathrm{~K}^{8}{ }^{8} 1 \mathrm{~K}$, $07^{48} 17,15^{44} 05$, and $03^{84} 13$ can have same direction and embedding scale as $R t^{\prime}$ s, though " $15^{44} 05^{\prime \prime}$ can get conflicts, whereas the X(-helix) extension (or XE in short) does not exist [i.e., $X=0$ ] : (1). ' $3 \mathrm{R}=4 B+1$ ' [i.e., $\mathrm{R}(16)+B(4)=\mathrm{R}(4)+B(20)+4$ ], R-embed towards right; (2). $' \mathrm{R}=4 B+1^{\prime}$ [i.e., $\mathrm{R}(12)+B(4)=\mathrm{R}(8)+B(20)+4$ ], R-embed towards left (yet also for $\mathrm{X} \neq 0$ here).

For Type $A$, one standard $X$ extension gets a node increment, $8+R(8)+B(8)$. The node increment in general embedding is the multiple of 4 , but the start position separation of $\mathrm{X}$ extensions (XE in short) is 2 . The mathematical non-divisibility can benefit causing no conflicts, especially on the embedding of the same direction, or R embeddings of Fig. 10.

Blocking, i.e., having constantly equivalent or even larger buffers can help prevent conflicts which are due to (embedding) direction difference. On $B$ embeddings of Fig. 10, "Lt $08^{4} 12$ vs Rt $12^{8} 08^{\prime \prime}$, "Lt $18^{8} 02$ vs Rt $02^{4} 18^{\prime \prime}$, “Lt $04^{4} 1 \mathrm{~J}$ vs Rt $1 \mathrm{~J}^{4} 04^{\prime \prime}$ and "Lt $14^{4} 0 \mathrm{~J}$ vs Rt $0 J^{4} 14^{\prime \prime}$ can consequently get conflict-free.

We consider shortest, longest holizontal distance of endnodes of Type-A networks in Fig. 10, Fig. 12, respectively. Fig. 11 deals with others; XE for blocking is needed or designed; linear extensions (LE in short) need to have acceptable configuration as case B.

Toplogically, LE and XE can be considered as special nodes. On Fig. 11, case A, XE

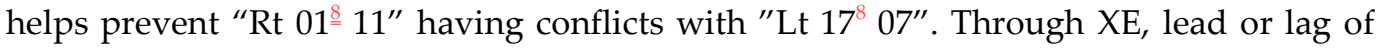
original nodes can be changed yet conflict-free. The visible location of nodes 06,12 of case A or nodes 00, 14 of case B of the pair networks are different, but nodes of physically same position are conflict-free if we check through tracing the route of XE than we can get confirmation.

Fig. 12, Lt XE starts at node 03 and Rt XE starts at node 10 originally with a lag distance, 2. Because XE is rhythmic and the embeddings are 'multiple of four' based so that extra add-in 2 can cause mathematical nondivisibility and create XE physically conflict-free. Similarly, Lt/Rt $12^{4} 00$ can be conflict-free.

On Fig. 13, case A, Tp $0 \mathrm{O}^{8} 1 \mathrm{O}$ needs to cmpare with $\mathrm{Bt} 1 \mathrm{M}^{8} 0 \mathrm{M}$ though they are conflict-free due to blocking. Tp $0 \mathrm{O}^{8} 1 \mathrm{O}$ has common contents, which are kept lagging within Bt $01^{4} 11$. Nodes $04,0 \mathrm{~L}, 1 \mathrm{~L}$ can be visibly different due to $\mathrm{XE}$, but physically same positioned nodes can be conflict-free, confirmed as the aforementioned tracing method. Case B, the Lt embedding can be equally divided into two parts, and each responses to embeddings totally having same quantity but different contents; consequently, for example, Lt $1 \mathrm{~K}^{\mathrm{L}} 0 \mathrm{~K}$ responses to Rt $01^{4} 11,13^{4} 03,05^{4} 15$, the contents are conflict-free.

On Fig. 14, case A, Lt $17^{4} 07$ has different direction of embedding as that of Rt $07^{4} 17$ even though their contents are same, yet their conflicts can be avoided by buffering. Lt $09^{4} 19$ or node 19 can have no conflicts because that LE length (E) being 4 is expelled. Lt $03^{8} 13$ can keep leading on its same contents in Rt $01^{4} 11$, and can keep leading on its same contents in Rt $05^{-} 15$ if XE is not built up or can keep lagging on its same contents in XE. Lt $05^{4} 15,0 \mathrm{~K}^{4} 1 \mathrm{~K}$ can keep leading. Case $\mathrm{B}$, node 08 can have no conflicts because that LE length (E) being 6 is expelled. Lt $14^{4} 0 \mathrm{~J}, 08^{4} 12,10^{4} 06$ can have enough distance or have no conflicts with Rt $0 \mathrm{~J}^{4} 14,12^{\underline{4}} 08,10^{4} 06$ if embedding exist. Lt $16^{8} 00$ and $1 \mathrm{~J}^{4} 04$ counted together can have same embedding scale-i.e., $\underline{12}$ as that of Rt $16^{4} 00$ and $18^{8} 02$, and can have same direction, so that they can have no conflicts, based on their sequence.

On Fig. 15, Lt $18^{4} 02$ has same embedding direction as Rt $18^{\underline{L}} 02$ and can be counted together with $\mathrm{Lt} 0 \mathrm{~J}^{8} 14$ in getting an equivalent block to let Lt $18^{4} 02$ keep leading and Lt $0 \mathrm{~J}^{8} 14$ keep lagging - compared to the same embedding content of Rt $12^{-8} 08$ and $00^{4} 16$. Rt $12^{\underline{8}} 08$ has same embedding direction as Lt $1 \mathrm{~J}^{\underline{L}} 04$; its same contents of $\mathrm{Lt}^{\underline{L}} 1 \mathrm{~J}^{\underline{L}} 04$ can keep their lagging, with Rt $00^{4} 16$ as the buffering.

On Fig.16, R-embd can have four typical sections with similarities in the compared two patterns. L/Rt OK ${ }^{4} 1 \mathrm{~K}, 19^{4} 09$, and $17^{8} 07$, and $(\mathrm{Lt}) 13^{8} 03 /(\mathrm{Rt}) 13^{\underline{\underline{8}}} 03$ can be considered 
as equivalent nodes in two different patterns, although the last one also can be adapted. The former three sections can keep their original order without conflicts; the last one can be conflict-free due to the non-divisibility of four as well as the basic distance of nodes 13 being two. Rt $13^{8} 03$ is adapted to $13^{4} 03$ if the XE physically exits; the contents of Lt $13^{8} 03$ still keep lagging, including those compared to same nodes on XE. Due to the non-divisibility of four and the basic distance of nodes 39 (the start of XE) being six, the $\mathrm{XE}$ can be conflict-free.

Fig.16, $B$-embd (L/Rt) $08^{4} 32,0 \mathrm{~J}^{4} 34$ can be collectively considered as a single node, and keep their original order and conflict-free. Lt $02^{8} 38$ has same contents with same embedding direction on Rt $02^{4} 38$ and those on Lt can keep leading. Yet, Lt $02^{8} 38$ has same contents with different embedding direction on Rt $36^{4} 00$ and those on Lt can keep lagging due to buffering from such as Lt $17^{8} 07,04^{4} 3 \mathrm{~J}$. Lt $04^{4} 3 \mathrm{~J}$ has same contents with same embedding direction on Rt $06^{8} 30$ and those on Lt can keep leading. Yet, Lt $30^{4} 06$ has same contents with different embedding direction on Rt $06^{8} 30$ and those on Lt can keep leading due to buffering from such as $\mathrm{Rt} 36^{4} 00,0 \mathrm{~J}^{4} 34$.

On Fig.17, case A, two $B$-embd directions are needed to prevent conflicts of nodes $2 \mathrm{~J}$, $1 \mathrm{~J}$ (if ' $\mathrm{R}=0, B=1$, e.g., $\mathrm{E}=0$ or not'). Lt $00^{4^{4}} 36$ and $06^{44} 30$ can keep lagging to $\mathrm{Rt} 36^{44} 00$ and $30^{44} 06$ of same contents, even though with different directions, due to enough buffering. In $\mathrm{Lt} / \mathrm{Rt}$, their $32^{44} 08,0 \mathrm{~J}^{44} 34,04^{44} 3 \mathrm{~J}$, and $38^{44} 02$ have consistent directions and same contents. It is easy to find that Lt $32^{44} 08,0 \mathrm{~J}^{44} 34$ can keep leading, and Lt $38^{44} 02$ can keep lagging, while Lt $04^{44} 3 \mathrm{~J}$ need to be checked. Firstly, assuming $04^{44}-3 \mathrm{~J}$ can be conflicted if $\mathrm{E}=0$, from eq. $(\mathrm{R}+\mathrm{B})(4+2 \mathrm{E})=2 \mathrm{E}+4 \mathrm{R}+4 \mathrm{~B}+4$, this assumption cannot be true. Then, assuming $04^{44} 3 \mathrm{~J}$ can be conflicted if $E \neq 0$, from eq. $4 B+8 R=4+2 E+4 B+R(4+2 E)$, or $R(4-2 E)=2 E+4$, or $E=2(R-1)(R+1)^{-1}$, this assumption still cannot be true. The above checks can support $04^{44} 3$ J conflict-free.

Fig. 17, case $A,(B \geq R$, except for ' $R=B=0$ if $8 \geq E \geq 4$ ') as the meaning implied in $\stackrel{8}{ }$, $R t$ $07^{48}=17$ can be adapted into $07^{44} 17$ and $X E$ if $X E>0$ (i.e., $X E$ exists) or $07^{48} 17$ if $X E=0$ (XE does not exist). No matter when $\mathrm{XE}$ exists, Lt $17^{44} 07$ keep lagging due to enough buffering even though directions of compared Rt $07^{48}=17$ are different. With the right (protrusive) direction and $\mathrm{XE}=0$, Rt $07^{4 \underline{8}} 17$ can keep leading compared to Lt $09^{44} 19$ due to having same direction and enough bufferings (due to accumulated embeddings). Lt $09^{44} 19$ and Rt $0 K^{84} 1 K$ can have some common contents and same direction. With the right direction, or style: $\mathrm{E}$ being positive, Lt $09^{44} 19$ can keep leading to Rt $0 \mathrm{~K}^{84} 1 \mathrm{~K}$ due to having enough separation. With the left direction, or style: $E$ being 0 , the non-divisibility can help them conflict-free because Lt 09 leads Rt $0 \mathrm{~K}$ four nodes in basic patterns, while node 09 is naturally counted two before node $0 \mathrm{~K}(\mathrm{~J}=10, \mathrm{~K}=11,11-9=2)$ in column 0 . Due to enough buffering, e.g., Rt $03^{44} 13,04^{44} 3 \mathrm{~J}$ (checking from the right side), compared to Lt $1 \mathrm{~K}^{4} 0 \mathrm{~K}$, the same contents in $\mathrm{Rt} 0 \mathrm{~K}^{84} 1 \mathrm{~K}$ can keep lagging. Lt $03^{\underline{8}}=13$ can be adapted into $03^{44} 13$ and $\mathrm{XE}$ if $\mathrm{XE}$ exists or $03^{84} 13$ if $\mathrm{XE}$ does not exist. Lt $03^{\underline{84}} 13$ or Lt XE adaptively have some common contents of Rt $03^{44} 13,01^{44} 11$ and Rt XE, and can be conflict-free due to their same direction and enough separation. The content, direction, and neighbor $04^{44} 3 \mathrm{~J}$ of Lt $15^{44} 05$ and Rt $15^{44} 05$ is same so that Lt/Rt $15^{44} 05$ can be conflict-free.

Nodes 10, 20, 21, and 31 of Lt/Rt pattern need restriction, i.e., $8 \geq E \geq 4$, to prevent conflicts while $B=0=\mathrm{R}$. Lt/Rt 27 and 37 are visually located at different positions if XE has been applied, yet the conflict-free of the same positioned nodes can be verified stepwisely along the XE. While XE does not exist, Lt 27 and 37 can keep leading.

Fig. 17, case $B$, restrictions such as $R>B$, rational $E$ values, and ' $B=0=R$ if $8 \leq E \leq 4$ ' can let nodes 15, 16, 20, and 10 conflict-free. R-embd, due to have enough separation, $\mathrm{Lt}$ $0 \mathrm{~K}^{48} 1 \mathrm{~K}$ can keep lagging with its common contents of $\mathrm{Rt} 0 \mathrm{~K}^{44} 1 \mathrm{~K}$; the former also can keep leading its common elements of Rt $01^{44} 11$; Lt $17^{44} 07$ can keep leading its common elements of Rt $07^{84} 17$. Rt $01^{44} 11$ can keep lagging to its common contents of Lt $03^{8{ }^{2}} 13$. Lt $09^{44}=19$ can keep lagging with its common contents of Rt $19^{44} 09$; their content difference, LE, shown in its right-embedding can pass conflict checking on Rt $0 K^{44} 1 K$, specifically on $\mathrm{XE}=0$, because a round of $\mathrm{XE}$ generates typical ' $16+\mathrm{R}(8)+B(8)$ ' nodes to help the $\mathrm{Rt}$ 
ones keep leading. On $\mathrm{XE}=0, \mathrm{Rt} 03^{48}=13$ in its right-embedding can pass conflict checking on Lt $05^{44} 15$, the former has common contents of Lt $03^{84}=13$ and keep lagging.

The following two examples are hoped to confirm that the requirement differentiation is needed. First, on preventing the conflict of Rt $07^{84} 17$ and $\mathrm{Lt} 17^{44} 07$, the equation, supported with the left protrusive style of R-emb. and the right protrusive style of B-emb., proves that Lt 17 can keep leading: ' $12+6 \mathrm{E}+\mathrm{R}(8+4 \mathrm{E})+\mathrm{B}(12+2 \mathrm{E})^{\prime}$ ' $\mathrm{R}(12+4 \mathrm{E})+\mathrm{B}(4)^{\prime}$ ', or ' $6 \mathrm{E}+(8+2 \mathrm{E}) \mathrm{B}-4 \mathrm{R}+12$ ' $>0$. Second, on preventing LE conflicts due to contexts related to adaptation, the equation, supported with the right protrusive style of $\mathrm{R}$-emb and the left protrusive style of B-emb., proves that Lt $09^{44} 19$ can prevent LE conflicts by adjusting requirements: assuming ' $R(4+2 E)+(R-1)(4+2 E)+B(4)+2=2 E+R(4)+B$ $(12+2 \mathrm{E})+10^{\prime}$, or ' $(4 \mathrm{R}-2 \mathrm{~B}-4) \mathrm{E}=8 \mathrm{~B}-4 \mathrm{R}+12^{\prime}$, or ' $\mathrm{E}=(-1)+(6 \mathrm{~B}+8)(4 \mathrm{R}-2 \mathrm{~B}-4)^{-1}$, , then no solution can be found in the requirement domain; i.e., the possible $\mathrm{E}$ is intentionally restricted to nothingness. If $B=R / 2$, the denominator ' $4 R-2 B-4$ ' is ' $6 B-4$ ', and ' $4 R-4$ ' if $B=0$. We may get a possible even $E, E=6$ if ' $B$ is 0,1 ' and ' $R$ is 2 '; however, this possibility is expelled in the domain through design.

If $X E>0$, those adaptations located on Lt XE can keep leading; nodes 23, 33, 09,19, 29, and 39 of both patterns can be found conflict-free through tracing their XE routes. Lt $00^{44} 36,34^{44} 0 \mathrm{~J}, 3 \mathrm{~J}^{44} 04$, and $06^{44} 30$ have same contents but different embedding directions with Rt $36^{\underline{4}} 00,0 \mathrm{~J}^{44} 34,04^{44} 3 \mathrm{~J}$, and $30^{44} 06$; they are conflict-free and keep the original leading-lagging order due to enough separation. Lt/Rt $32^{44} 08$ and $38^{44} 02$ have same contents and keep the original leading-lagging order.

Fig. 18, the extension direction of LE attached nodes need be checked to verify no conflicts on them. Shown as the left/right superscript modules, let $B=B r$ if $B<R$, and $B l=R$, $\mathrm{Br}=\mathrm{B}-\mathrm{Bl}$, if $\mathrm{B} \geq \mathrm{R}$, Node 15 , assuming conflicts exist first, then $\mathrm{Bl}(8+2 \mathrm{E})+\mathrm{Br}(4)+\mathrm{E}+2=\mathrm{R}(8+2 \mathrm{E})$, or $\mathrm{E}=(-4)+2(1-2 \mathrm{Br})(2 \mathrm{Bl}-2 \mathrm{R}+1)^{-1}$; it is irrational. Similarly, node 21 , no reasonable $\mathrm{E}$ can solve the equation, $B l(8+2 \mathrm{E})+\mathrm{E}+2=\mathrm{R}(4+2 \mathrm{E}), \quad \mathrm{E}=(-4)+[2-4(B r+\mathrm{R})](2 B l-2 \mathrm{R}+1)-1$. The LE attached to node Rt 36 has same extension direction as that of Lt 35, and can keep lagging, but node 36 itself can keep leading.

Fig. 18 , the embedding of Lt $26^{-8} 16$ or $22^{-8} 12$ versus Rt $20^{\mathrm{L}} 10$ has the same extension direction, and location separation for possible conflict must be $2(\bmod 4)$, which is impossible if separation is $0(\bmod 4)$. Rt $33^{-8} 23$ can be conflict-free with $\mathrm{Lt}^{2} 31^{\underline{8}} 21$ and $33^{44}-23$ due to same embedding direction and enough separation. Similarly, Rt $37^{\frac{48}{2}} 27$ and Lt $31^{\underline{8}} 21$ can be conflict-free. Rt $25^{4 \underline{4}} 35$ and Lt $35^{\underline{48}} 25$ can be conflict-free due to the assistance from Rt $33^{84} 23$ and enough separation even though their embedding direction are different. Lt $35^{\frac{48}{2}} 25$ can be conflict-free with $\mathrm{Rt} 37^{\frac{48}{2}} 27$ due to same embedding direction and enough separation.

Fig. 19, R-embd. 05t 15 in both patterns can essentially has no influence because they can be considered as conflict-free specific nodes. All specific LE attached nodes have same direction without conflicts. Interchanging $B$-embd can create enough separation and conflict protection.

Fig. 20, The XE of both patterns starts at the same location. The XE can cause adaptations only in R-embd. Assuming $X E=0$ first, the common contents of Lt $09^{\underline{L}} 19$ and Rt $01^{\stackrel{8}{=}} 11$ can be kept leading in Lt, while the common contents of Lt $09^{\underline{L}} 19$ and Rt $07^{\stackrel{8}{=}} 17$ can be kept lagging in Lt due to the networked order; similarly, the common contents of Lt $07^{\stackrel{4}{*}} 17$ and Rt $07^{\stackrel{8}{-}} 17$, Lt $05^{4} 15$ and Rt $05^{4} 15$ can be kept leading.

Then assuming $\mathrm{XE}>0$, due to enough separation, including LE, the adaptation caused by XE can be conflict-free. Through XE tracing, nodes 12, 22 of one pattern can be conflict-free to their corresponded real positioned nodes, instead of 12, 22 of another pattern. Each pattern has four B-embd. Their contents are pair-wise same, but two pairs are embedded in different directions. All of them can be conflict-free due to enough separation.

Fig. 21, case A, R being 0 , all $B$ embeddings can be considered as specific nodes due to their identity. With enough separation, all $B$-embd. and LE attached nodes can be conflict-free. Case B, with enough separation, all B-embd. R-embd. and LE attached 
nodes can be conflict-free. For example, conflict-free Rt 02 gets support from $\mathrm{R}>0$. R-embd. adopts composing style to build up a balancing platform to avoid conflicts; specifically, Rt $26^{4} 16$ and $20^{8} 10$ can get an equivalent and same-direction embedding scale like Lt $24^{\underline{L}} 14$.

Fig. 22, LE attached nodes can be conflict-free due to enough separation. $\mathrm{Lt}^{07^{8}} 17$ can well keep lagging with Rt and help Lt $13^{\mathrm{L}} 03$ prevent conflicts with Rt $07^{-}-17$. Rt $19^{4}$ $09^{\prime}$ s common contents in $13^{L} 03$ can keep lagging. Rt $13^{4} 03$ can keep leading with Lt $13^{\underline{L}}$ 03 due to enough separation.

Fig. 23, the conflict-free of both patterns is supported by same direction, enough separation, and non-divisibility of four. Lt $00^{4} 25$ can keep lagging to Rt $00^{4} 25$; their difference, LE in the embedding can keep leading to the LE of Lt $27^{4} 02$. Rt $27^{4} 02,23^{4} 08$ escape collisions $(\equiv 0(\bmod 4))$ with $\operatorname{Lt}^{2} 7^{4} 02,23^{\underline{8}} 08$. respectively, due to distance (三 $2(\bmod 4))$. Rt $21^{\underline{8}} 06$ can keep lagging with the same contents in Lt $23^{\underline{\underline{s}}} 08,29^{4} 04$ due to enough separation.

Fig. 23, if $X E>0$, different from others, nodes 03, 13, 23, 08, 18, 28 will appear at different locations in the pattern comparison. Nodes 18, 28 of Lt pattern lag if $\mathrm{XE}=0$, so it can keep lagging if $\mathrm{XE}>0$. As for other four nodes, those of Lt are two nodes behind those of Rt and the start location of XE; hence, the XE generated those new LT four nodes still can be two nodes behind those of Rt.

Fig. 24, no collision can be found in LE attached nodes; for example, on sensitive 13, the second one of both patterns, has same direction. Lt $05^{\ddagger} 15$ and Rt $03^{\ddagger} 13$ have same embedding content and direction, so they have no conflicts. Other nodes can easily be found conflict-free.

\section{References}

1. Schmidt, R.; Austin, S. Adaptable Architecture: Theory and Practice; Routledge: Abingdon, London, UK, 2016; pp. 15-19, ISBN 9780415522571.

2. Gottdiener, M.; Budd, L. Key Concepts in Urban Studies; Sage: Thousand Oaks, CA, USA, 2005; pp. 100-104, 121-125, ISBN 9780761940982.

3. Corburn, J. Equitable and healthy city planning: towards healthy urban governance in the century of the city. In Healthy Cities: The Theory, Policy, and Practice of Value-Based Urban Planning; Leeuw, E. Simos, J. Eds.; Springer: New York, NY, USA, 2017; pp. 31-41, ISBN 9781493966943.

4. Corburn, J. Healthy City Planning: From Neighbourhood to National Health Equity; Routledge: Abingdon, London, UK, 2013; pp. 2-8, p. 112, ISBN 9780203772249.

5. Venturi, R. Complexity and Contradiction in Architecture, $2^{\text {nd }}$. Ed.; The Museum of Modern Art, New York, NY, USA, 1997; p. 11, pp. 34-36, p. 54, ISBN 9780870702822.

6. Risen, C. Electricity substation, Virkkunen \& Co. J.AIA2020, 109(3), 35-37. https://www.architect magazine.com/design/ kalasatama-electricity-substation-and-suvilahti-graffiti-fence-by-virkkunun-co-architects_o

7. MEAE (Ministry of Economic Affairs and Employment). Finland's Integrated Energy and Climate Plan; Government Administration Department, Publications: Helsinki, Finland, 2019; p. 34, p. 56, ISBN 9789523274785. https://ec.europa.eu/ energy/sites/ener/files/documents/fi_final_necp_main_en.pdf

8. Amadei, B.; Wallace, W. Engineering for humanitarian development. IEEE TES2009, 28(4), 6-15.

9. Gerfan, K.; Staudenmaier, E. Geffen academy at UCLA, Los Angeles, Koning Eizenberg Architecture. J.AIA2019, 108(6), 102-107. https://www.architectmagazine.com/project-gallery/geffen-academy-at-ucla_o

10. Hsu, L.-Y. Parallelism enhancing cellular communication - on knowledge city evolving. In Proceedings of the 13th World Congress on Intelligent Control and Automation; WCICA IEEE, Changsha, China, July 4-8, 2018; pp. 100-107, ISBN 978153867346.

11. Lynch, K. A Theory of Good City Form; MIT Press: Cambridge, MA, USA, 1981; pp. 119-130, ISBN 9780262620468.

12. Leeuw, E. Cities and health from the neolithic to the anthropocene. In Healthy Cities: The Theory, Policy, and Practice of Value-Based Urban Planning; Leeuw, E. Simos, J. Eds.; Springer: New York, NY, USA, 2017; pp. 3-30, ISBN 9781493966943.

13. Haeusermann, T. The dementia village: between community and society. In Care in Healthcare: Reflections on Theory and Practice; Krause, F. Boldt, J. Eds.; Palgrave Macmillan: Switzerland, 2018; pp. 135-167, ISBN 9783319612911.

14. Smith A. Architects are combating COVID-19 with site adaptation. J.AIA2020, 109(5), 122. https://www.architectmagazine. com/aia-architect/architects-are-combating-covid-19-with-site-adaptation_o 
15. Keane, K. As the virus spreads, architects are building health care infrastructure capacity. J.AIA2020, 109(5), 160-163. https: //www.architectmagazine.com/practice/these-architects-are-addressing-covid-19- health-care-infrastructure-capacity_o

16. Cramer, N. COVID-19 should change us (editorial). J.AIA2020, 109(4), 104. https://www.architect magazine.com/design/ editorial/covid-19-should-change-us_o

17. Boldt, J. et al. Conclusion: asking the right questions. In Care in Healthcare: Reflections on Theory and Practice; Krause, F.; Boldt, J. Eds.; Palgrave Macmillan: Cham, Switzerland, 2018; pp. 282-291, ISBN 9783319612911.

18. Hu, Z.; Chen, T.; Ge, Q.; Wang, H.; Observable degree analysis for multi-sensor fusion. In Multi-Sensor Information Fusion; Jin, X.-B.; Gao, Y. Eds.; MDPI: Basel, Switzerland, 2020; pp.25-44, ISBN 9783039283033.

19. Hsu, L.-Y. Interactive placemaking - prototype of an intelligent urban building infrastructure for critical borderlands / Kinmen. MAS2018., 12(7), 128-143. https://doi.org/10.5539/mas. 2n7p128

20. van der Meide, H. Towards a three-dimensional perspective of space for humanizing hospital care. In Care in Healthcare: Reflections on Theory and Practice; Krause, F.; Boldt, J. Eds.; Palgrave Macmillan: Cham, Switzerland, 2018; pp. 265-281, ISBN 9783319612911.

21. Lucini, B. The Other Side of Resilience to Terrorism: A Portrait of a Resilient-Healthy City; Springer: Cham, Switzerland, 2017; pp. 5-18, p. 26, p. 31, p.60, ISBN 9783319569437.

22. Graham, S. Cities, war, and terrorism: towards an urban geopolitics. In Cities, War, and Terrorism: Towards an Urban Geopolitics; Graham, S. Ed.; Wiley-Blackwell: Hoboken, NJ, USA, 2004; pp.30-53, ISBN 9781405115759.

23. Tilly, C. Terror as strategy and relational process. Int. J. Comp. Sociol.2005, 46(1-2), 11-32. DOI: 10.1177/0020715205054468.

24. Levy, S. Project Management in Construction; McGraw-Hill: New York NY, USA, 2007; pp. 253-259, pp. 355-369, ISBN 9780071464178.

25. FEMA (Federal Emergency Management Agency) FEMA 430: Site and Urban Design for Security- Guidance Against Potential Terrorist Attacks; Dept. Homeland Security, USA, 2007; pp. ii-iii, Ch.1p.7, Ch.2p.30, Ch.3p.18, Ch.4p.32, Ch.5p.2, http://www.fema.gov/media-library-data/20130726-1624-20490-9648/fema430.pdf

26. Andersen, P.; Solomon, D.; Carson, D. The Architecture of Patterns; W. W. Norton \& Company: New York, NY, USA, 2010; p. 17, p. 47, pp. 79-82, p. 86, ISBN 9780393732931.

27. Brugger, L.; Minnery, R.; Fifth Estate Communications (eds) AIA Disaster Assistance Handbook, $3^{\text {rd }}$ ed.; American Institute of Architects: Washington, DC, USA, 2017; p. 8, pp. 90-94. http://content.aia.org/sites/default/files/2017-05/ Disaster_Assistance_Handbook_050917.pdf

28. Sussman, J. Perspectives on Intelligent Transportation Systems (ITS); Springer: New York, NY, USA, 2005; p. 33, p. 47, p. 55, p. 203, p. 219, ISBN 9781441935908.

29. Rittel, H.; Webber, M. Dilemmas in a general theory of planning. Policy Sci.1973, 4(2), 155-169. https://doi.org/10.1007/ BF01405730

30. Fisher, T. Public values and the integrative mind: how multiple scores can collaborate the city building. Public Adm. Rev2014, 76(4), 457-464. https://doi.org/10.1111/puar.12133

31. Braha, D.; Maimon, O. A Mathematical Theory of Design: Foundaions, Algorithms and Applications; Springer: New York, USA, 1998; p.5, pp.33-44, ISBN 9781441947987.

32. de Neufville, R.; Scholtes, S. Flexibility in Engineering Design; MIT press, Cambridge, MA, USA, 2011; pp. 15-30, ISBN 9780262016230.

33. Syrett, M.; Devine, M. Managing Uncertainty: Strategies for Surviving and Thriving in Turbulent Times; Profile Books, London, UK, 2012; pp. 11-13, ISBN 9781846685903.

34. Salingaros, N. Architecture, patterns, and mathematics. Nexus Netw.J1999, 1(1-2), 75 - 85. https://doi.org/10.1007/ s00004-998-0006-0

35. Hillgren, P.-A.; Seravalli, Q.; Emilson, A. Prototyping and infrastructuring in design for social innovation. CoDesign2011, 7(3-4), 169-183.

36. Rappaport, T. Wireless Communications: Principles and Practice; Prentice Hall: Upper Saddle River, NJ, USA, 2002; pp. 57-60, ISBN 9780130422323.

37. Anderson, J.; Kalra, N.; Stanley, K.; Sorensen, P.; Samaras, C.; Oluwatola, O. Autonomous Vehicle Technology - A Guide for Policymakers; RAND Corporation: Santa Monica, CA, USA, 2016; pp. 71-80. http://www.rand.org/pubs/ research_reports/RR443-2.html

38. (AIA-staff) What's next: making sense of the smart city. J.AIA2019, 108(1), 64-65. https://www.architectmagazine.com/design/ making-sense-of-the-smart-city_o

39. Lau, W. (ed.) What is a smart city? we're working on it. J.AIA2019, 108(1), 92-99. https://www.architectmagazine.com/ technology/q-a-what-is-a-smart-city-three-experts-explain_o

40. Hsu, L.-H.; Lin, C.-K. Graph Theory and Interconnection Networks; CRC press: Boca Raton, FL, USA, 2008; pp. 1-30, pp. 40-42, p.79, p.141, p.152, pp. 303-304, pp. 417-419, ISBN 9781420044812.

41. Van Wijk, A.; van de Roest, E.; toere, J. Solar Power to the People; IOS press: Amsterdam, Netherlands, 2017; pp. 5-6, ISBN 9781614998327.

42. Flynn, K. Designing a trash-free future. J.AIA2018, 107(6), 159 - 160. http://www.architect magazine.com/aiaarchitect/aiafuture/designing-a-trash-free-future_o 
43. Scission, P. Why high-tech parking lots for autonomous cars may change urban planning. Curbed2016, (Aug). http://www.curbed.com/2016/8/8/12404658/autonomous-car-future-parking- lot-driverless-urban-planning

44. Ayobi, A. Carlo Ratti Associati designs first smart highway system in Italy. J.AIA2018, 107(1). (e-version only) https://www.architectmagazine.com/technology/carlo-ratti-associati-designs-first-smart-highway-system-in-italy_o (accessed on 31 July 2021)

45. Risen, C. Uber Sky tower: citation. J.AIA2019, 108(7), 116-119. https://www.architectmagazine.com/ awards/r-d-awards/citation-uber-sky-tower-reimagines-the-future-of-air-transport_o

46. Dickinson, E. Future proofing. J.AIA2019, 108(1), 86-87. https://www.architectmagazine.com/design/future-proofing-the -smart -city_o

47. Keane, K. Elements of a smart city. J.AIA2019, 108(1), 70. https://www.architectmagazine.com/design/ elements-of -a-smart-city_o

48. Hurley, A. MIT on the "future of suburbia." J.AIA2016, 105(5), $179-188$. http://www.architect magazine.com /design/culture/the-future-of-suburbia-according-to-mit_o

49. Hsu, L.-Y. Sustainable placemaking at Taiwan's shoreline - thinking from Hsinchu / the shortest path across the Taiwan Strait. In Bridging the East and West: Theories and Practices of Transportation in the Asia Pacific; Shon, J., Tseng, P.-Y., Chen, C.-H., Lo, S.-C., Eds.; ASCE: Reston, VA, USA, 2016; pp. 79-85, ISBN 9780784479810.

50. Sowers, S. Autonomous vehicles come to babcock ranch. J.AIA2018, 107(10). (e-version only) https://www. architectmagazine.com/design/autonomous-vehicles-come-to-babcock-ranch_s (accessed on 31 July 2021)

51. Honesty, L. (video producer) Checking in with SCAD's parking garage micro community. J.AIA2015, 104(6), 6. https://www.architectmagazine.com/videos/checking-in-with-scads-parking-garage-micro-community (accessed on 31 July 2021)

52. King, A. Koda house. J.AIA2016, 105(7). (e-version only) http://www.architectmagazine.com/project-gallery/koda -house_o (accessed on 31 July 2021)

53. Grant, R. Contemporary Strategy Analysis, $8^{\text {th }}$ ed.; Wiley: Chichester, UK, 2013; p. 112, pp. 419-420, ISBN 9781119941880.

54. Hill, C.; Schilling, M.; Jones, G. Strategic Management: Theory E Cases: An Integrated Approach, 12 ${ }^{\text {th }}$ ed.; Cengage: New York, NY, USA, 2017; p. 46, p. 84, ISBN 9781305081765.

55. Robbins, S.; Coulter, M. Management, $11^{\text {th }}$ ed.; Prentice Hall: Upper Saddle River, NJ, USA, 2012; p. 473, ISBN 9780132163842.

56. Schneekloth, L.; Shibley, R. Placemaking: The Art and Practice of Building Communities; Wiley: Hoboken, NJ, USA, 1995; pp. 109-120, p. 229, ISBN 9780471110262.

57. Sassen, S. Epilogue (urbanizing technology). In Citizen's Right to the Digital City: Urban Interfaces, Activism, and Placemaking, $1^{\text {st }}$ ed.; Foth, M., Brynskov, M., Ojala, T., Eds.; Springer: New York, NY, USA, 2015; pp. 252-256, ISBN 9789812879196.

58. Schuler, D. Community networks and the evolution of civic intelligence. AI Soc.2010, 25(3), 291-307, DOI:10.1007/ s00146-009-0260-z.

59. Hasan, S.; Siddique, N.; Chakraborty, S. Intelligent Transport Systems: 802.11-based Roadside-To-Vehicle Communications; Springer: New York, NY, USA, 2013; pp. 8-9, ISBN 9781461432715.

60. Picone, M.; Busanelli, S.; Amoretti, M.; Zanichelli, F.; Ferrari, G. Advanced Technologies for Intelligent Transportation Systems; Springer, New York, NY, USA, 2015; pp. 12-18, pp. 82-83, ISBN 9783319106687

61. Li, F. Interference Cancellation Using Space-Time Processing and Precoding Design; Springer: New York, NY, USA, 2013; pp. 2-3, ISBN 9783642307126.

62. Keeble, L. Principles and Practice of Town and Country Planning, $4^{\text {th }}$ ed.; Estates Gazette, London, UK, 1969; p. 112, ISBN 978-0900361050.

63. Batty, M.; Longley, P. Fractal Cities: A Geometry of Form and Function; Academic Press: London, UK, 1994; pp. 7-8, ISBN 9780124555709.

64. Hoppe L; Awsede L. Design of control of UAV objects. In Advanced Technologies for Intelligent Systems of National Border Security; Nawrat, A., Simek, K., Swieriak, A., Eds.; Springer: New York, NY, USA, 2013; pp. 211-220, ISBN 9783642316647.

65. Sankaran, S.; Khota, L.; Panigrahib, S. Biology and applications of olfactory sensing system: a review. Sens. Actuator B-Chem.2012, 171-172(1), 1-17, https://doi.org/10.1016/j.snb.2012.03.029

66. Allen, C., Taking narrow channel collision prevention seriously to more effectively manage marine transportation system risk. JMLC2010, 41(1), 1-56. https://madden-maritime.com/wp-content/uploads/2016/09/article_2010_allen_narrow -channels.pdf

67. Fritteli, J. Port and Maritime Security: Background and Issues; Nova Science: Hauppauge, NY, USA, 2008; pp.17-1 9, p. 158, ISBN 1590338235.

68. Wong, M.-C.; Yip, T.-L. Maritime piracy: an analysis of attacks and violence. IJSTL2012; 4(4), 306-322, DOI:10.1504/ IJSTL.2012.049315.

69. Boemmich, E. et al. On the future of Argo: a global, full-depth, multi-disciplinary array. Front. Mar. Sci.2019; https://doi.org/ 10.3389/fmars.2019.00439 (accessed on 31 July 2021) 
70. Knox, R.; Douglass, D. Recent energy balance of earth. IJG2010; 1(1), 99-101, DOI: 10.4236/ijg.2010.13013

71. Stojmenovic, I. Honeycomb networks: topological properties and communication algorithms. IEEE T Parall Distr.1997, 8(10), 1036-1042, DOI: 10.1109/71.629486.

72. Cho, H.-J.; Hsu, L.-Y. Generalized honeycomb torus. Inf. Process. Lett.2003; 86(4); 185-190, DOI: 10.1016/S00200190(02)00507-0.

73. Knezevic, J. Systems Maintainability: Analysis, Engineering and Management; Chapman Hall: London, UK, 1997; p. 11, p. 221, ISBN 0412802708.

74. Kao, S.-S.; Hsu, L.-H.; Spider web networks: a family of optimal, fault tolerant, Hamiltonian bipartite graphs. Appl Math. Comput.2005; 160(1), 269-282, DOI: 10.1016/j.amc.2003.06.005.

75. Kao, S.-S.; Hsu, L.-H. Hamiltonian laceability of spider web networks. JCYU2005; 33(1), 1-10, DOI: 10.6358/JCYU. 200503.0001

76. Teng, Y.-H.; Tan, J.; Ho, T.-Y.; Hsu, L.-H. On mutually independent Hamiltonian paths. Appl. Math. Lett. 2006; 19(4), 345-350, DOI:10.1016/j.aml.2005.05.012.

77. Hsu, L.-Y.; Ling, F.-I.; Kao, S.-S.; Cho, H.-J. Ring embedding in faulty generalized honeycomb tori - GHT(m,n,n/2) Int J Comput Math.2010; 87(15), 3344-3358, DOI: 10.1080/00207160903315524.

78. Hsu, L.-Y.; Lin, T.-Y.; Kao, S.-S. The Hamiltonian laceability of some generalized honeycomb tori. AIP Conf. Proc.2008; 1060(1), 302-306, https://doi.org/10.1063/1.3037078. .

79. Collas, G. Reliability Engineering for The Future. In New Trends in System Reliability Evaluation, $1^{\text {st }}$ ed.; Misra, K. Ed.; Elsevier: Amsterdam, Netherlands, 2012; pp. 1-8, ISBN 9780444565266

80. Daley, D. Design for Reliability: Developing Assets That Meet The Needs of Owners; Industrial Press: New York, NY, USA, 2011; p. 19, p. 178, p. 203, ISBN 9780831134372.

81. Birolini, A. Reliability Engineering: Theory and Practice, 5 ${ }^{\text {th }}$ ed.; Springer: New York, NY, USA, 2007; p. 17, ISBN 9783540493884 . 